\title{
The BLLAST field experiment: Boundary-Layer Late Afternoon and Sunset Turbulence
}

M. Lothon ${ }^{1}$, F. Lohou $^{1}$, D. Pino ${ }^{2,24}$, F. Couvreux ${ }^{3}$, E. R. Pardyjak ${ }^{4}$, J. Reuder ${ }^{5}$, J. Vilà-Guerau de Arellano ${ }^{6}$,

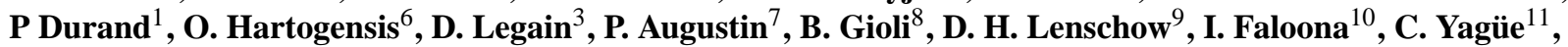
D. C. Alexander ${ }^{4}$, W. M. Angevine ${ }^{12}$, E Bargain $^{1}$, J. Barrié ${ }^{3}$, E. Bazile ${ }^{3}$, Y. Bezombes ${ }^{1}$, E. Blay-Carreras ${ }^{2}$, A. van de Boer ${ }^{6,25}$, J. L. Boichard ${ }^{13}$, A. Bourdon ${ }^{14}$, A. Butet ${ }^{14}$, B. Campistron ${ }^{1}$, O. de Coster $^{6}$, J. Cuxart ${ }^{15}$, A. Dabas ${ }^{3}$, C. Darbieu ${ }^{1}$, K. Deboudt ${ }^{7}$, H. Delbarre ${ }^{7}$, S. Derrien ${ }^{1}$, P. Flament ${ }^{7}$, M. Fourmentin ${ }^{7}$, A. Garai ${ }^{16}$, F. Gibert ${ }^{17}$, A. Graf ${ }^{18}$, J. Groebner ${ }^{19}$, F. Guichard ${ }^{3}$, M. A. Jiménez ${ }^{20}$, M. Jonassen ${ }^{5}$, A. van den Kroonenberg ${ }^{21}$, V. Magliulo ${ }^{26}$, S. Martin ${ }^{22}$,

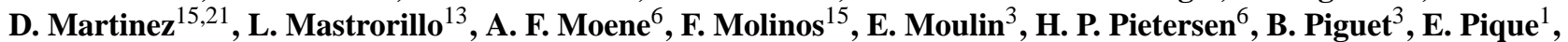
C. Román-Cascón ${ }^{11}$, C. Rufin-Soler ${ }^{23}$, F. Saïd ${ }^{1}$, M. Sastre-Marugán ${ }^{11}$, Y. Seity ${ }^{3}$, G. J. Steeneveld ${ }^{6}$, P. Toscano ${ }^{8}$,

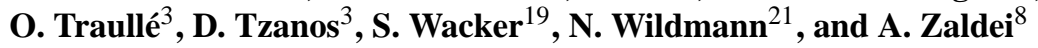

${ }^{1}$ Laboratoire d'Aérologie, University of Toulouse, CNRS, France

${ }^{2}$ Applied Physics Department, Barcelona Tech UPC, Barcelona, Spain

${ }^{3}$ CNRM-GAME (UMR3589, Météo-France and CNRS), Toulouse, France

${ }^{4}$ University of Utah, Salt Lake City, Utah, USA

${ }^{5}$ Geophysical Institute, University of Bergen, Bergen, Norway

${ }^{6}$ Meteorology and Air Quality Section, Wageningen University, Wageningen, the Netherlands

${ }^{7}$ Laboratoire de Physique et Chimie Atmosphériques, Université du Littoral Côte d'Opale, Dunkerque, France

${ }^{8}$ Institute of Biometeorology - National Research Council (IBIMET-CNR), Florence, Italy

${ }^{9}$ National Center for Atmospheric Research, Boulder, Colorado, USA

${ }^{10}$ Land, Air and Water Resources, UC Davis, California, USA

${ }^{11}$ Dpt. Geofísica y Meteorología, Universidad Complutense de Madrid, Facultad Ciencias Físicas, Madrid, Spain

${ }^{12}$ CIRES, University of Colorado, and NOAA ESRL, Boulder, Colorado USA

${ }^{13}$ SEDOO, OMP, Toulouse, France

${ }^{14}$ Service des Avions Français Instrumentés pour la Recherche en Environnement, CNRS-CNES-Météo-France,

Francazal, France

${ }^{15}$ Departament de Fisica, Universitat de les Illes Balears, Palma de Mallorca, Spain

${ }^{16}$ Mechanical and Aerospace Engineering, University of California, San Diego, California, USA

${ }^{17}$ Laboratoire de Météorologie Dynamique, Ecole Polytechnique, Palaiseau, France

${ }^{18}$ Institut für Bio- und Geowissenschaften, Juelich, Germany

${ }^{19}$ PMOD-WRC, Davos Dorf, Switzerland

${ }^{20}$ Mediterranean Institute for Advanced Studies (UIB-CSIC), Esporles, Illes Balears, Spain

${ }^{21}$ University of Tübingen, Tübingen, Germany

${ }^{22}$ Technische Universitaet Braunschweig, Braunschweig, Germany

${ }^{23}$ Institut de Recherches en ENvironnement Industriel (IRENI), Dunkerque, France

${ }^{24}$ Institut of Space Studies of Catalonia (IEEC-UPC), Barcelona, Spain

${ }^{25}$ Meteorological Institute, University of Bonn, Bonn, Germany

${ }^{26}$ Institute of Mediterranean Agricultural and Forest Systems - National Research Council (ISAFOM-CNR), Naples, Italy

Correspondence to: M. Lothon (marie.lothon@ aero.obs-mip.fr)

Received: 23 March 2014 - Published in Atmos. Chem. Phys. Discuss.: 29 April 2014

Revised: 8 August 2014 - Accepted: 5 September 2014 - Published: 16 October 2014 
Abstract. Due to the major role of the sun in heating the earth's surface, the atmospheric planetary boundary layer over land is inherently marked by a diurnal cycle. The afternoon transition, the period of the day that connects the daytime dry convective boundary layer to the night-time stable boundary layer, still has a number of unanswered scientific questions. This phase of the diurnal cycle is challenging from both modelling and observational perspectives: it is transitory, most of the forcings are small or null and the turbulence regime changes from fully convective, close to homogeneous and isotropic, toward a more heterogeneous and intermittent state.

These issues motivated the BLLAST (Boundary-Layer Late Afternoon and Sunset Turbulence) field campaign that was conducted from 14 June to 8 July 2011 in southern France, in an area of complex and heterogeneous terrain. A wide range of instrumented platforms including full-size aircraft, remotely piloted aircraft systems, remote-sensing instruments, radiosoundings, tethered balloons, surface flux stations and various meteorological towers were deployed over different surface types. The boundary layer, from the earth's surface to the free troposphere, was probed during the entire day, with a focus and intense observation periods that were conducted from midday until sunset. The BLLAST field campaign also provided an opportunity to test innovative measurement systems, such as new miniaturized sensors, and a new technique for frequent radiosoundings of the low troposphere.

Twelve fair weather days displaying various meteorological conditions were extensively documented during the field experiment. The boundary-layer growth varied from one day to another depending on many contributions including stability, advection, subsidence, the state of the previous day's residual layer, as well as local, meso- or synoptic scale conditions.

Ground-based measurements combined with tetheredballoon and airborne observations captured the turbulence decay from the surface throughout the whole boundary layer and documented the evolution of the turbulence characteristic length scales during the transition period.

Closely integrated with the field experiment, numerical studies are now underway with a complete hierarchy of models to support the data interpretation and improve the model representations.

\section{Introduction}

At interface between the earth's surface and the atmosphere, the planetary boundary layer (PBL) is a critical component of the earth system. It mediates the transfer of heat, momentum, humidity and trace gases between the surface and the atmosphere. The PBL over land has a strong diurnal cycle. On a fair weather day, as the sun rises, the surface heating warms the air above, which mixes by turbulent processes within an increasingly deep layer, engulfing air from the free atmosphere above (Stull, 1988; Garratt, 1992). Conversely, during the night, the radiatively cooled surface stratifies the air above, which forms a stable nocturnal boundary layer. Both midday and nocturnal periods, when in a stationary state, have been relatively successfully modelled, even if several issues remain open (see the reviews by Angevine, 2008; Cuxart, 2008; and Holstlag et al., 2013). Morning and evening transitions remain difficult to observe and model, in large part due to their inherent transience. The late afternoon transition typically starts from a well-mixed convective boundary layer (CBL) and transforms to a residual layer overlying a stably-stratified surface layer. This evolving boundary layer exhibits complex characteristics such as turbulence intermittency and enhancement of anisotropy, horizontal heterogeneity, rapidly changing conditions and combinations of weak forcing mechanisms.

The evolution of the PBL has been studied since the 1950s. An extensive knowledge of the diurnal evolution of the PBL and its influence on the pollutant distribution has been obtained since then (Vilà-Guerau de Arellano et al., 2004, 2009; Casso-Torralba et al., 2008). The increasing knowledge of PBL processes has been based on two main types of studies: the application of the theoretical concepts of turbulence (Batchelor, 1967; Tennekes and Lumley, 1973; Pope, 2000; Wyngaard, 2010) to perform numerical simulations of atmospheric characteristics (Lilly, 1967; Deardorff, 1972; Lenschow, 1974; Stull, 1976; Moeng, 1984; Jacobson, 2000; Pielke, 2002; Stensrud, 2007), and detailed field observations (e.g. Wangara: 1967, Kansas: 1968 or Minnesota: 1973, described in Hess et al., 1981 and Kaimal and Wyngaard, 1990, remain fundamental references). There have been a large number of intensive field experiments since then, and in addition, systematic observations now made at some observatories allow the exploration of the PBL on a long-term basis as well: for example, at Lindenberg, Germany (Beyrich and Engelbart, 2008), Cabauw, the Netherlands (Van Ulden and Wieringa, 1996; Hurley and Luhar 2009; Baas et al., 2009; Bosveld et al., 2014) and CIBA, Spain (Yagüe and Cano, 1994), as well as flux monitoring networks worldwide.

Most PBL studies were previously devoted to investigating the PBL characteristics and the relevant processes during midday, when unstable or neutral conditions usually prevail (Kaimal et al., 1976; Mahrt and Lenschow, 1976; Stull, 1988; Moeng and Sullivan, 1994; Cuijpers and Holtslag 1998), or at night when a stable atmosphere is typically found (Nieuwstadt, 1984; Debyshire, 1990; Garratt 1992; Cuxart et al., 2000; Poulos et al., 2002 van de Wiel et al., 2003; Mahrt, 2014). Limited-area and global meteorological models, as well as air quality models have largely benefited from these 
investigations by introducing new process-based parameterizations.

As early as the late 1970s, though, André et al. (1978) compared a third-order moment model with ground-based measurements and soundings of the boundary layer during an entire diurnal cycle. Difficulties were found in the nocturnal conditions and during the late afternoon transition. Several recent studies have attempted to simulate the entire diurnal cycle both with large-eddy simulation (LES) and singlecolumn parameterized models (SCM). These include Kumar et al. (2006), Basu et al. (2008) or Svensson et al. (2011), who made use of realistic conditions based on the Horizontal Array Turbulence Study (HATS, Horst et al., 2004), Wangara and CASES-99 campaigns, respectively. Beare et al. (2006) and Edwards et al. (2006) compared surface observations at Cardington, UK, with respectively a LES and a SCM from early afternoon to the next morning. The late afternoon transition decay was delayed in the LES relative to the observations, but a large improvement was found when assimilating the observations. The single-column model had difficulties for correctly representing turbulence diffusion during the afternoon transition, which affected the mean profiles. Most of the numerical simulations quoted above are able to reproduce the multi-layering that occurs in the evening and the generation of a nocturnal jet, but the transition timing remains hard to catch for several important variables (including surface fluxes, mean wind and temperature, and friction velocity). In addition, most of the simulations described above could only be compared with surface measurements of fluxes and turbulence and with vertical profiles of mean variables, but rarely with turbulence observations up to the PBL top.

There are still relatively few observational studies dedicated to the transitory processes in the cloud-free or shallowconvective PBL, e.g. Grant (1997) (in Cardington, UK), Brazel et al. (2005) (Phoenix Air Flow Experiment), Fernando et al. (2004), Fernando et al. (2013) (The Phoenix Evening Transition Flow Experiment). Also notable are the LIFT/FLATLAND experiment (Cohn et al., 2002) in the plains of Illinois, LITFASS (Beyrich et al., 2006) over heterogeneous surface in Germany, and CASES-99 (Poulos et al., 2002) in Kansas for the study of the nocturnal stable boundary layer. Without being specifically dedicated to the afternoon and evening transitions, these observational campaigns were the basis of key studies on the late afternoon or evening transitions.

The results based on the previously mentioned campaigns and on numerical experiments revealed some key issues of the late afternoon transition, which were chosen as the guideline for the Boundary-Layer Late Afternoon and Sunset Turbulence (BLLAST) project. In the following section, we present in more detail the issues raised by the afternoon transition, based on the background of previous studies. Section 3 describes in detail the experimental set-up and strategy that were chosen to address those issues, and Sect. 4 points out the potential of the BLLAST data set to bring some answers.
This general manuscript therefore introduces the deeper analyses made on specific issues that are made in the other articles of the special issue.

\section{Addressed issues}

This section reviews the previous studies that are addressing the afternoon transition and turbulence decay. We first remind several definitions proposed in the literature for the period and layers of interest, then investigate the past results on the turbulence decay process and finally discuss the potential impacts of the transition and benefits from improved understanding.

\section{1 "Convective", "mixed" or "residual" layers? Definition and scaling}

Definitions of the afternoon transition (AT) and the evening transition (ET) (and distinctions between them) may vary according to previous studies. In the study by Nadeau et al. (2011), the AT starts as soon as the surface sensible heat flux begins to decrease and ends when it becomes negative. Grimsdell and Angevine (2002) have used different subjective criteria based on UHF wind profiler measurements, in order to analyse the behaviour of the CBL top (estimated from the reflectivity) with respect to the depth of the layer with a significant amount of turbulence (estimated from the spectral width). In their study, the AT start is defined as (i) the time when the vertical structure close to the top begins to "decouple" or the turbulence starts to decay at the top or (ii) the time when the CBL top starts to descend. (i) or (ii) were considered on distinct days, depending on the behaviour of the CBL top: (i) was used for cases with an "inversion layer separation" and (ii) for cases with a descent of the CBL top. Defined as such, the AT usually lasts several hours. Grimsdell and Angevine (2002) found that the transition was gradual and not sudden, from a CBL-top perspective. The ET is usually defined as the period of time from zero surface sensible heat flux to a well-established nocturnal stable layer, with quasi-steady depth.

In the context of the AT and ET, the definitions of the surface layer, the mixed layer (and CBL), the residual layer and the nocturnal stable boundary layer have to be carefully revisited.

Criteria typically used to define the depth of the CBL during midday are, among others, the depth of well-mixed scalars, the depth of significant turbulence, the depth of increasing relative humidity, the height of the capping inversion or of minimum buoyancy flux (Angevine et al., 1994; Moeng and Sullivan, 1994; Seibert et al., 2000; Zhu and Albrecht, 2002; Brooks and Fowler, 2011). These criteria all find approximately the same depth in a well-defined CBL, but they start to evolve differently during the AT and may separate from each other as observed, e.g. by Grimsdell and 
Angevine (2002): the depth of the CBL may decrease, while the residual inversion remains level or evolves on its own depending on advection and subsidence.

In unstable conditions, the surface layer is mainly governed by shear and buoyancy, and the outer layer above is governed by buoyancy. Consequently, during the day, in convective conditions, most of the boundary-layer processes in the outer layer can typically be scaled based on the surface buoyancy flux and the boundary-layer height (Deardorff scaling, Deardorff, 1970; Willis and Deadorff, 1976). In the surface layer, the Monin-Obukhov similarity theory (MOST, Monin and Obukhov, 1954) has been widely used. Both scalings are the basis for robust parameterizations in bulk and mesoscale models. However, during the afternoon transition, the surface buoyancy flux decreases toward zero, and the influence of other competing processes as radiation, advection, entrainment or wind shear become relatively more important. So neither the convective scaling, nor the MOST-based stable boundary-layer scaling, are valid. It is therefore necessary to explore the validity of convective and stable scalings, and how to represent the transition using non-dimensional analysis or new scalings. In this context, van Driel and Jonker (2011), based on an idealized LES and 0-D model study of a non-stationary PBL, suggest considering the time it takes for the energy to travel from the surface up to the top of the boundary layer. McNaughton et al. (2007), Sorbjan (2010, 2012) and Kumar et al. (2006) also proposed new scalings that could be tested in the context of transitory phases, like the local Richardson number and Nieuwstadt scalings. A question that is still poorly understood is the following: how long does the CBL remain quasi-stationary during the AT, or, equivalently, for how long does the convective scaling apply as the surface flux decreases?

\subsection{Turbulence decay process}

\subsubsection{Turbulence kinetic energy (TKE) decay}

Several authors have previously studied the transition regimes of turbulence with laboratory experiments (e.g. Monin and Yaglom, 1975; Cole and Fernando, 1998). The first LES study of the decaying atmospheric convective mixed layer was performed by Nieuwstadt and Brost (1986). The authors analyzed an academic case of a sheared, clear mixed layer, in which turbulence decayed as a result of a sudden shut-off of the upward surface sensible heat flux. In both the LES simulations and the laboratory experiments, the turbulent kinetic energy is found to decay following a power law $t^{-n}$ of time $t$.

Later, Sorbjan (1997) considered a gradual change of the heat flux with time, in response to the decreasing of the elevation of the sun. The evolution of the decaying sheared mixed layer was shown to be governed by two timescales: the external (or "forcing") timescale $\tau_{\mathrm{f}}-$ that is the timescale of the gradually changing of the heat flux - and the convective timescale $t_{*}=Z_{i} / w_{*}$, where $Z_{i}$ is the CBL depth, and $w_{*}$ is the convective velocity scale (Deardorff, 1970; Willis and Deardorff, 1976). In this context, the power coefficient $n$ is a function of $\tau_{\mathrm{f}} / t_{*}$.

Recently, Nadeau et al. (2011) considered a realistic decrease of the surface sensible heat flux, based on observations of the LITFASS-2003 experiment (Beyrich and Mengelkamp, 2006). They showed that the TKE decay phase can be separated in two stages: first, a slow decay during the AT followed by a rapid collapse of turbulence during the ET. Also Nadeau et al. (2011) were able to model the decay observed in the surface layer with a model based on a mixed-layer parameterization, rather than on a surface-based parameterization. Based on the CASES-99 data set, Rizza et al. (2013) performed a LES study of the decay phase whose results corroborate the findings of Nadeau et al. (2011).

In both laboratory experiments and numerical studies, such as those mentioned above, the decay of the turbulent kinetic energy is found to depend on the formulation of the decrease in the surface-atmosphere energy exchanges (e.g. either expressed as prescribed surface sensible heat fluxes or surface temperature), but with no consensus on the exact relationship between the forcing and the power law.

On the observational side, Fitzjarrald et al. (2004) provided aircraft measurements of the turbulence decay within the PBL, and revealed a sharper and more systematic decay of the wind vertical velocity relative to the horizontal components. Most of the other previous observational studies have focused on the decay of the TKE in the surface layer (e.g. Fernando et al., 2004; Brazel et al., 2005), with little quantification of how turbulence is decaying in the upper levels, and how the different levels interact with each other.

\subsubsection{The evolution of length scales}

Characteristic scales of turbulence are relevant for understanding and quantifying PBL processes and their representation in meteorological models. Various length scales can be considered to characterize turbulence processes, with different ways to estimate them including the wavelength of the energy spectrum peak (energy production), the integral scale (energy-containing eddies) or other scales defined with a weighted integral of the spectrum, and also the buoyancy length scale, the Ozmidov scale (that is the scale where the buoyancy forces affecting the vertical momentum are equal to the inertial forces; Fernando, 1991), etc. During midday, those are often proportional (Lenschow and Stankov, 1986), but this is not expected to remain valid in the late afternoon. As parts of the boundary layer become stably stratified, the buoyancy length and Ozmidov scale (Fernando, 1991), etc., become relevant. For the Phoenix Airflow Experiment, the observations of Pardyjak (2001) indicate that these two scales decrease quite linearly in the hours following ET.

Indeed, there is a lack of agreement in the evolution of the vertical velocity characteristic length scale during the late 
afternoon transition, partly due to the difficulty of addressing the issue, both with numerical studies and observations. Vertical motions up to $1 \mathrm{~m} \mathrm{~s}^{-1}$ extending horizontally over several $\mathrm{km}$ have been observed, weaker but of larger scale than the midday eddies (Aupetit, 1989). Possible explanations for those include growth of boundary-layer scales, or surface variability and orography that can induce mesoscale circulations.

By using LES, Nieuwstadt and Brost (1986) found that the length scale of the vertical velocity spectrum peak remained constant during the decay process. The study by Sorbjan (1997) mentioned previously reflected that small eddies had a tendency to decay earlier than large eddies. Consequently, organized convection persisted in the decaying mixed layer even when the buoyancy flux at the surface became negative, and a nocturnal inversion was being developed near the earth's surface. These results were later confirmed by the direct numerical simulation of Shaw and Barnard (2002).

Pino et al. (2006) have shown that the characteristic length scale, based on a weighted integral of the energy spectrum, has a different evolution during the decay. They found that the characteristic length scales increase with time, for all variables but the vertical velocity, for which the scale remained almost constant. Based on tethered-balloon observations, Grant (1997) showed that the peak of the vertical velocity spectra shifts to smaller length scales during the ET in the surface layer, and remains steady above.

With the TKE decay itself, the evolution of the characteristic length scales has been one of the main questions addressed in the past studies on the afternoon transition. However, the scale issue remains unclear and only partly understood. A thorough investigation of whether the scales in the mixed (and then residual) layer really increase or decrease is necessary. In addition, it must be understood whether the characteristic length scales decrease in the surface layer as the nocturnal boundary layer starts to build, as stated by Kaimal and Finnigan (1994).

Another important related question is the anisotropy of the turbulence. Fitzjarrald et al. (2004) with flux towers and aircraft measurements and Pino et al. (2006) by means of LES showed that the turbulence does not relax to an isotropic state during the decay process. Contrarily, Monin and Yaglom (1975) found in laboratory experiments that the turbulence maintains the initial isotropy during the decay. Lothon et al. (2006) have found with midday lidar observations in the CBL that the ratio between longitudinal (i.e. along the sampling direction) and transverse (i.e. perpendicular to the sampling direction) vertical velocity integral scales was smaller than it would be in isotropic turbulence, i.e. the turbulence is "squashed". The surface layer data from Pardyjak (2001) also indicated that vertical turbulence was damped and isotropy rapidly increased. However, it remains unclear how squashed it remains later and until sunset.

\subsubsection{Competing influences: "the unforced transition"}

The decay of turbulence and the evolution of the characteristic length scales need to be related to the relevant forcing mechanisms, not only to the rate of surface buoyancy decrease, but also to competitive forces or processes generated by clouds, entrainment, radiative processes, shear and advection. Angevine (2008) suggests the term of "unforced transition", because those processes are usually weak during the later part of the AT, but all may come into play.

The following questions are raised by the AT and ET periods:

- How does entrainment evolve during the AT? What is its role in the afternoon transition? Nieuwstadt and Brost (1986) suggested that large eddies are still active for some time in driving entrainment at the top of the residual layer, in spite of the decoupling from the surface. This was corroborated numerically by Pino et al. (2006), but still needs to be confirmed by observations and further study. Canut et al. (2012) with a LES, found an increase in the entrainment rate in the late afternoon. The evolution of entrainment has to be linked to the evolution of scales. Van Heerwaarden et al. (2009) and Lohou et al. (2010) have shown how entrainment can have impact down to the surface, with signatures on evaporation or integral scales, respectively. Thus, the evolution of the entrainment process needs to be linked with the evolution of length scales throughout the entire depth of the boundary layer.

- What is the influence of radiation in the decay process? Since the surface buoyancy flux is weak, radiation divergence can make a significant contribution during this period, both at the surface and at the top of the mixed layer (Steeneveld et al., 2010).

- What is the role of land-use and surface heterogeneity in the evolution of turbulence intensity and scales? How do the heat storage in the ground or vegetation canopy and radiative long-wave and short-wave components come into play? Pardyjak and Fernando (2009) and Nadeau et al. (2011) have studied the turbulence decay in the surface layer over several types of surface and proposed a simple model for the decay in the convective surface layer. But the role of surface heterogeneity on the dynamics of the decaying CBL has still not been sufficiently addressed.

- How do the processes of the AT and ET interact with the flow reversal that occurs in mountainous or coastal areas, forced by mesoscale pressure and temperature gradients? Recently, the TRANSFLEX (The Phoenix Evening transition Flow Experiment; Fernando et al., 2013) and MATERHORN (Fernando and Pardyjak, 2013) experiments addressed the issue of the flow 
reversal over mountain slopes during the evening transition. With tethered-balloon observations and tracers along the slopes, Fernando et al. (2013) showed the complexity of the flow adjustment, with the generation of multiple fronts in the flow reversal process. The AT and ET in complex terrain need to be specifically addressed, since they precede the shifting of a valley wind circulation, or sea breeze.

\subsection{Potential impacts}

Finally, the AT and ET may have important impacts on the transport, mixing and distribution of trace species, the set-up of a nocturnal jet, or on the daytime growth of the followingday PBL.

\section{What is the impact of this transition on the transport of scalar species?}

During the evening transition, Acevedo and Fitzjarrald (2001) reported occurrences of specific humidity jumps, and drops in surface temperature, accompanied by an abrupt decay in wind velocity. Similarly, Mahrt et al. (1999) observed that the latent heat flux during evening events decreased more slowly than the strength of turbulence and the boundary-layer depth. This led to the significant moistening of the surface layer. This was also recently reported by Bonin et al. (2013) with unmanned aerial systems.

Recent studies (Vilà-Guerau de Arellano et al., 2004; Casso-Torralba et al., 2008) have shown that morning and afternoon transition are also important for the exchange of species. In early morning, when high entrainment rates have been observed, the remaining pollutants of the residual layer are introduced in the shallow boundary layer, thus increasing or decreasing their concentration. In the evening, the residual part overlying the stable layer can be incorporated in the free troposphere, so that water vapour and chemical components emitted at the surface and diluted into the convective layer during the day can be introduced in the free atmosphere and transported at larger scale, and in several layers (Banta et al., 1998; Berkowitz et al., 1998).

\section{How do the AT and ET interact with the appearance of the nocturnal jet?}

Mahrt (1981; 1999) pointed out that the evolution of the stress divergence during evening transitions increased the ageostrophic wind, and led to the development of a low-level jet (wind speed maximum), accompanied by decoupling of the flow just above the surface.

The large number of studies originating from the CASES97, CASES-99 and SABLES-98 experiments (Cuxart et al., 2000, Poulos et al., 2002) provide a comprehensive documentation of the stable and very stable boundary layers and their turbulence regimes (van de Wiel et al., 2003; Sun et al., 2012), giving a better understanding of nocturnal drainage flows (Soler et al., 2002) and of the nocturnal jet (Banta et al., 2003), and proposing explanations for turbulence intermittency (van de Wiel et al., 2002a, b; Sun et al., 2003; Cuxart and Jiménez, 2007). CASES-99 also nicely documents the evening transition. Lundquist et al. (2003) for example revisited the explanations and occurrence of inertial oscillations. However, the role of the AT and ET in setting auspicious or unfavourable conditions for the appearance of the nocturnal jet and occurrence of turbulence intermittency still needs to be further addressed.

\section{The BLLAST field experiment}

The issues presented above motivated several research groups (listed in Table 1) to plan and execute a dedicated field experiment that focused on the afternoon and evening transitions, with a dense array of complementary observations in time and space from the mid-afternoon to the night.

The BLLAST field campaign took place in early summer, from 14 June to 8 July 2011 in France. The site is called "Plateau de Lannemezan", a plateau of about $200 \mathrm{~km}^{2}$ area, a few kilometre from the Pyrenean foothills (Fig. 1), and about $45 \mathrm{~km}$ from the highest peaks of the Spanish border. The surface is covered by heterogeneous vegetation: grasslands, meadows, crops and forest (Fig. 2). The campaign combined in situ measurements from towers, balloons and airplanes with ground-based remote sensing. The measurements were intensified during the AT on days with favourable conditions (discussed later in the text), called intensive observation periods (IOPs).

Two sites (hereafter "sites 1 and 2") contained most of the ground-based instruments and were the focus of flight operations. There were two main observational strategies, which focused on (1) vertical structure and (2) spatial heterogeneity. A third supporting site (site 3) was instrumented to allow the estimation of the 3-D wind circulation, advection terms and spatial variability at the sub-mesoscale.

In the following, we first describe the observations made continuously during the field experiment, and second, those specifically made during the IOPs. The last subsections present the forecast model support during the field campaign, educational aspects, and the available data set.

\subsection{Continuous observations}

\subsubsection{Boundary-layer profiling}

Several remote-sensing instruments were deployed during BLLAST over the 3 sites for continuous monitoring of the atmosphere. Vertical profiling of the wind from $10 \mathrm{~m}$ to $16 \mathrm{~km}$ a.g.l. was accomplished at site 1 with a combination of sodar (from $10 \mathrm{~m}$ to $300 \mathrm{~m}$ a.g.1.), ultra-high frequency (UHF) radar (from $200 \mathrm{~m}$ to $3000 \mathrm{~m}$ a.g.l.) and very high frequency (VHF) radar (from $1.5 \mathrm{~km}$ to $16 \mathrm{~km}$ a.g.l.) profilers. Both the UHF and the sodar profiling systems can also measure some 
Table 1. Groups involved in the BLLAST campaign and the instrumentation they implemented.

\begin{tabular}{ll}
\hline Country, group & Instrumentation \\
\hline France, LA & Wind profilers, surface station, tethered balloon, radiosounding \\
France, CNRM-GAME & Wind profiler, lidar, ceilometer, scintillometer, surface station, \\
& turbulent probe under tethered balloon, frequent radiosounding \\
France, SAFIRE & Piper Aztec aircraft \\
France, LPCA & Sodar, surface station, SMPS and cascade impactor \\
France, LMD & Doppler lidar \\
the Netherlands, MAQ & Sodar, scintillometer, surface station \\
USA, Utah Univ. & Surface station, tethered balloon \\
USA, UC Davis & Radiosoundings \\
Italy, CNR & Sky Arrow aircraft \\
Spain, Univ. Comp. de Madrid & Microbarometers \\
Spain, Universitat de les Illes Balears & Surface station, soil measurements \\
Norway, Univ. Bergen & SUMO RPAS, surface station \\
Germany, Univ. Tübingen & MASC RPAS \\
Germany, Univ. Braunschweig & M2AV RPAS \\
Germany, Univ. Lipp & Octo-copter RPAS \\
Germany, Univ. Heidelberg & Sirius I RPAS \\
Germany, Univ. Bremen & BUSCA RPAS, Funjet1 RPAS, Funjet2 RPAS \\
Switzerland, PMOD-WRC & Radiation sensors \\
UK, Univ. Reading & Sensors on SUMO RPAS \\
\hline
\end{tabular}

characteristics of atmospheric turbulence (the turbulent energy dissipation rate can be estimated with a UHF profiler, and the temperature structure coefficient with a sodar). The UHF profiler also estimates the height of the mixed layer, or of any strong vertical gradients in the atmosphere (Angevine et al., 1994; Héo et al., 2003).

In addition, another UHF profiler and a sodar were deployed at sites 2 and 3, respectively (Fig. 1), to build a triangle of wind profilers, allowing the estimation of the 3-D wind at the scale of the plateau.

Lidars were also extensively utilized in the campaign. Two backscatter lidars, deployed at sites 1 and 2, monitored the aerosol vertical structure continuously. They provided estimations of the boundary-layer top and depth of aerosol layers. A Doppler lidar was also operated at site 1 , and provided profiles of the vertical wind at about $5 \mathrm{~s}$ time interval.

A ceilometer at site 1 supplied the cloud-base height. A full sky camera was collocated with the ceilometer and provided a qualitative monitoring of the cloud cover with an image of the entire sky every minute.

\subsubsection{Surface-layer measurements on various landscapes}

During the BLLAST experiment, seven surface sites, hereafter denoted "ss1" to "ss7", were instrumented above various vegetation types and for different objectives (Figs. 2 and 3). The sites characteristics (altitude, vegetation type and height), the measured variables and the sensors used are listed in Tables A1 and A2 of the Appendix. In addition to classical meteorological measurements, all the sites had high-frequency sensors measuring turbulence properties. All eddy-covariance sensing systems were mounted at heights that ensure that the instruments were in the constant flux layer (above $\sim 3-5$ times the height of the local roughness elements), except the instruments mounted at the forest site where this was not possible. The first aim of those stations was to provide a thorough description of the surface fluxes in the heterogeneous landscape of BLLAST area, while airborne and scintillometer measurements give access to integrated estimates. Beyond this, most of the surface stations were implemented with other dedicated objectives:

- At ss1 (at site 1) (Fig. 3a), two masts equipped for measuring all the terms of the surface energy balance were installed in a grass and a wheat field, respectively. A third station with a sonic anemometer and a water vapour and $\mathrm{CO}_{2}$ fast sensor was located at the edge between both fields. Measurements from these stations are being used to investigate the Monin-Obukhov similarity theory over a heterogeneous terrain by using a fluxfootprint model (van de Boer et al., 2013).

- The ss2 (at site 1) (Fig. 3d) was composed of two $10 \mathrm{~m}$ towers $20 \mathrm{~m}$ apart. The first tower was equipped with six sonic anemometers (at 0.85, 1.12, 2.23, 3.23, 5.27 and $8.22 \mathrm{~m}$ ) and nine fast-response fine-wire thermocouples (at $0.019,0.131,0.191,0.569,1.12,2.23,3.23$, $5.27,8.22 \mathrm{~m}$ ). The second tower had 6 long-wave radiation sensors installed at the same heights as the sonic anemometers. The aim of this set-up was to investigate near-surface long-wave radiation and buoyancy flux divergence, and the delay between the surface flux sign 


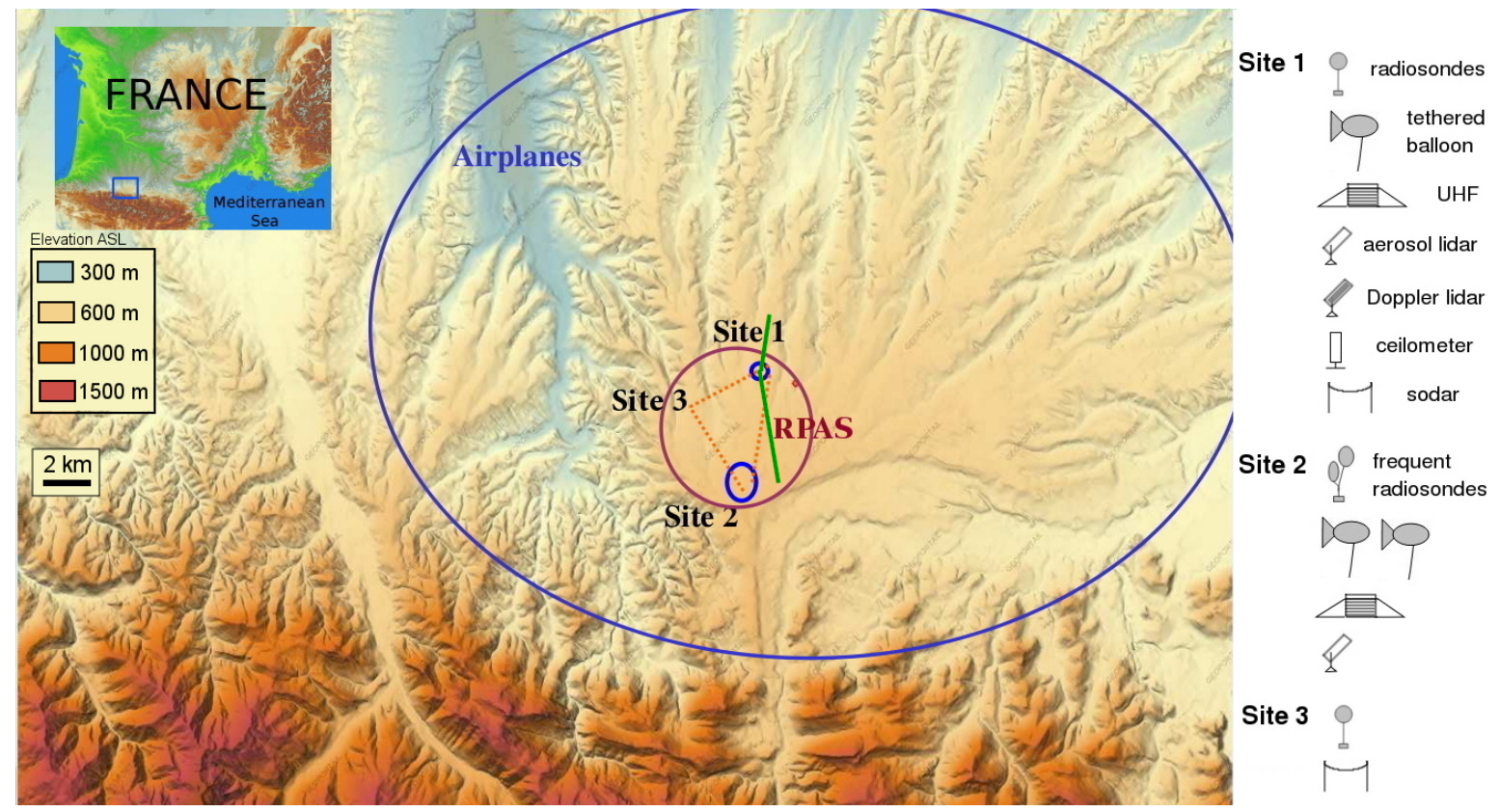

Figure 1. Experimental area. The small frame at the top-left corner situates the BLLAST experiment area (blue square) at the larger scale of the country. The large blue oval delimits the exploration area of the manned aircraft, and the smaller purple circle indicates the temporary restricted area (TRA) for the operations of the remotely piloted aircraft systems (RPASs). The orange dotted triangle locates the profiler network, and the green lines represent the paths of the two large aperture scintillometers. Instruments (other than surface stations) deployed over the three sites are schematized on the right side of the figure.

change and the temperature gradient sign change (BlayCarreras et al., 2014b), as well as the formation of extremely shallow flows (Manins and Sawford, 1979; Mahrt et al., 2001).

- The ss3 (at site 1) (Fig. 3e) focused on a small-scale (a few meters) surface heterogeneity study (Cuxart et al., 2014). A flat surface $(150 \mathrm{~m} \times 150 \mathrm{~m})$, covered with a mix of bare soil, small bushes, grass and small puddles, which constituted a very heterogeneous surface, had its soil characteristics (temperature, humidity) extensively mapped. The vertical air temperature profile in the first $1.5 \mathrm{~m}$ and the energy fluxes were also monitored.

Three high-resolution micro-barometers were also deployed at ss3, at each vertex of a triangle with $150 \mathrm{~m}$ side length, $1 \mathrm{~m}$ a.g.l. These high-precision digital instruments can detect very small pressure perturbations, of the order of $0.1 \mathrm{~Pa}$, at $2 \mathrm{~Hz}$ sampling frequency. The objective was to study the small-scale static pressure fluctuations produced in the atmospheric boundary layer due to turbulent motions or the propagation of waves of different types (Viana et al., 2009, 2010; Sastre et al., 2012; Román et al., 2014).

- The ss 4 is composed of the $60 \mathrm{~m}$ tower (Fig. 3b) which is a permanent platform at the Centre de Recherches Atmosphériques (CRA). It provides year-round flux measurements and a vertical profile of turbulence close to surface. At the top of the tower, a high-resolution IR camera $\left(1 \mathrm{~Hz}\right.$ image frequency of a $45^{\circ} \times 34^{\circ}$ field of view) pointed either toward the ss2, or toward the ss3 (Garai et al., 2013).

- At site 2, eddy-covariance stations sampled three contiguous large areas (about $1-2 \mathrm{~km}$ long) with relatively homogeneous vegetation: forest (ss5) (Fig. 3c), maize (ss6) and moor (ss7). The site was specifically devoted to the study of the role of surface heterogeneity. The turbulence characteristics and decay over the different vegetation covers will be compared taking into account the local circulations which may develop between the fields during this phase of the day.

For consistency, uniform data processing was carried out for all eddy-covariance stations mentioned above.

In addition to the previous measurements, three scintillometers were used. They measured the structure parameter of refractive index and temperature averaged along the path between the transmitter and the receiver (Moene et al., 2009). Therefore, and with the help of MOST, they provide an integrated measurement of surface fluxes over the heterogeneous regions sampled by the set of surface stations. A double beam laser scintillometer with a $110 \mathrm{~m}$ path length was deployed at ss1 (Hartogensis et al., 2002) and two large aperture scintillometers with path lengths of 3 and $4 \mathrm{~km}$ were aimed toward the north and the south-east, respectively (Fig. 2). 


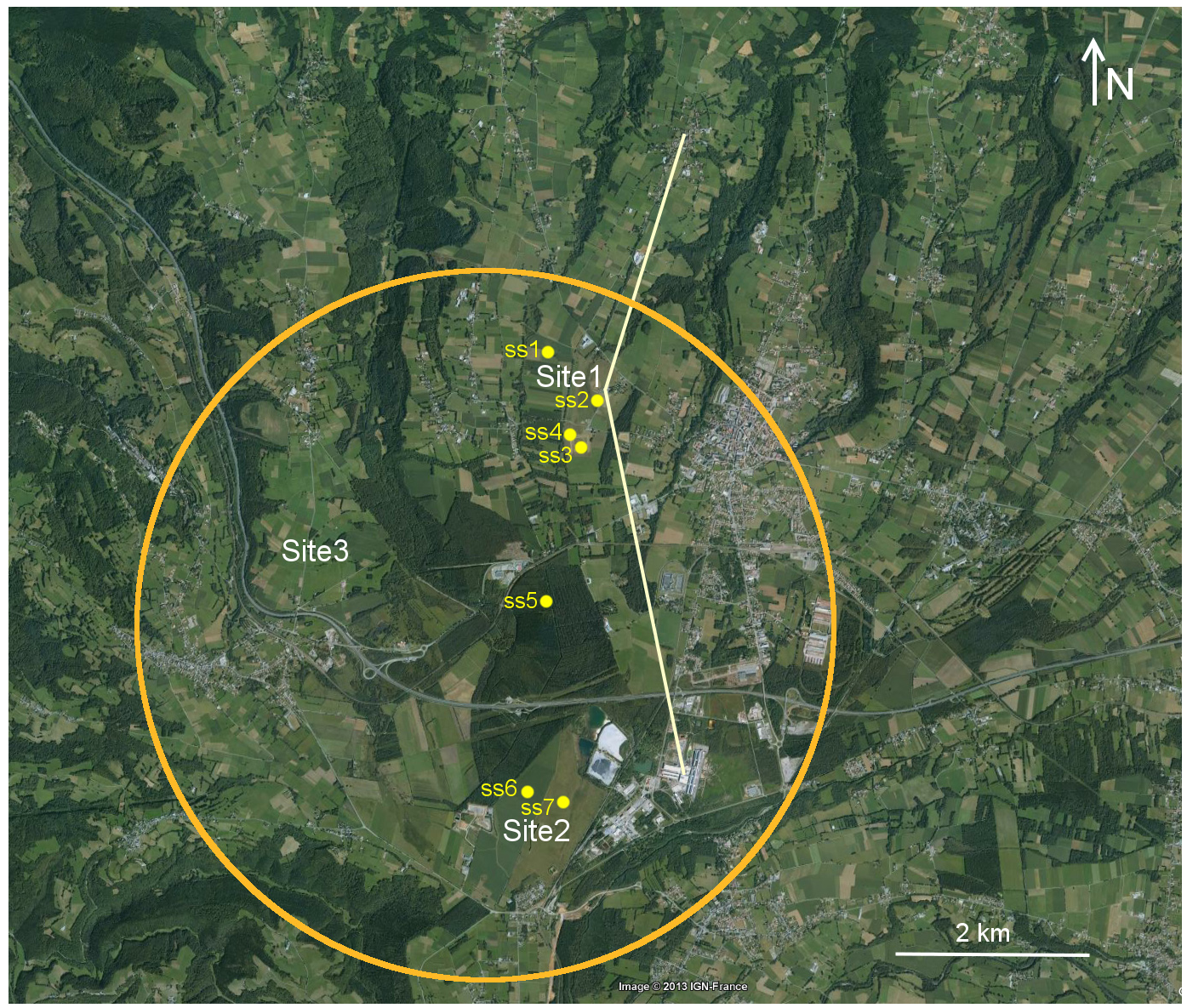

Figure 2. Satellite view (from Google Earth) of the area, showing the instrumented site locations. Surface sites over various vegetation are noted ss1 to ss7: (ss1) wheat, grass and edge; (ss2) prairies; (ss3) micro-scale surface heterogeneities; (ss4) 60 m tower; (ss5) forest; (ss6) maize; and (ss7) moor. The light yellow lines represent the paths of the two large aperture scintillometers and the orange circle indicates the limit of the TRA.

Finally, for the purpose of characterizing aerosol optical properties and studying aerosol effects on the evolution of the boundary layer, aerosols size distribution was monitored at site 1, by use of a ground-based Scanning Mobility Particle Sizer (SMPS; range $10 \mathrm{~nm}-1 \mu \mathrm{m}$ ) and an optical counter (OPC; range $0.3-20 \mu \mathrm{m}$ ). For sulfates analysis, a proxy for secondary aerosols formation, aerosols were also collected at $12 \mathrm{~m}$ height, using a three-stage cascade impactor, with cut-off diameters of $10 \mu \mathrm{m}, 100$ and $30 \mathrm{~nm}$.

\subsection{Intensive observation periods (IOPs)}

Observations were intensified under fair-weather conditions, with mostly dry convection during the day, and clear sky or fair weather cumuli during the afternoon and evening transitions. These characteristics correspond to anti-cyclonic conditions (mountain-plain breeze regime), post-frontal conditions, or weak-pressure gradient conditions. These situations are not specific to the AT and ET studies but typical for convective boundary-layer studies for which the influence of so- lar radiation on surface-atmosphere interaction plays a major role. Some IOP days were conducted the day following a rain episode when the morning was cloudy and conditions cleared up by midday. Over the 3.5 weeks of the field campaign, there were 12 days with favourable conditions (corresponding to 12 IOPs).

During the IOPs, two manned aircraft, remotely piloted aircraft systems (RPASs), tethered and ascending balloons, and in situ aerosol measurements were operated intensively. Figure 4 illustrates the observational strategy utilized during BLLAST IOPs and Table 2 summarizes the operation for each IOP.

For the joint operations of balloons, airplanes and RPASs, a temporary restricted airspace (TRA) was issued and activated daily from 05:00 to 21:30 UTC (note that 05:00 UTC is 07:00 LT). The TRA covered an area of $4 \mathrm{~km}$ radius including sites 1, 2 and 3 with an upper limit of $1.6 \mathrm{~km}$ a.g.l (see Figs. 1 and 2). While activated, only the two manned BLLAST research aircraft were allowed to enter the TRA. In these cases all RPASs and tethered-balloon operations were 


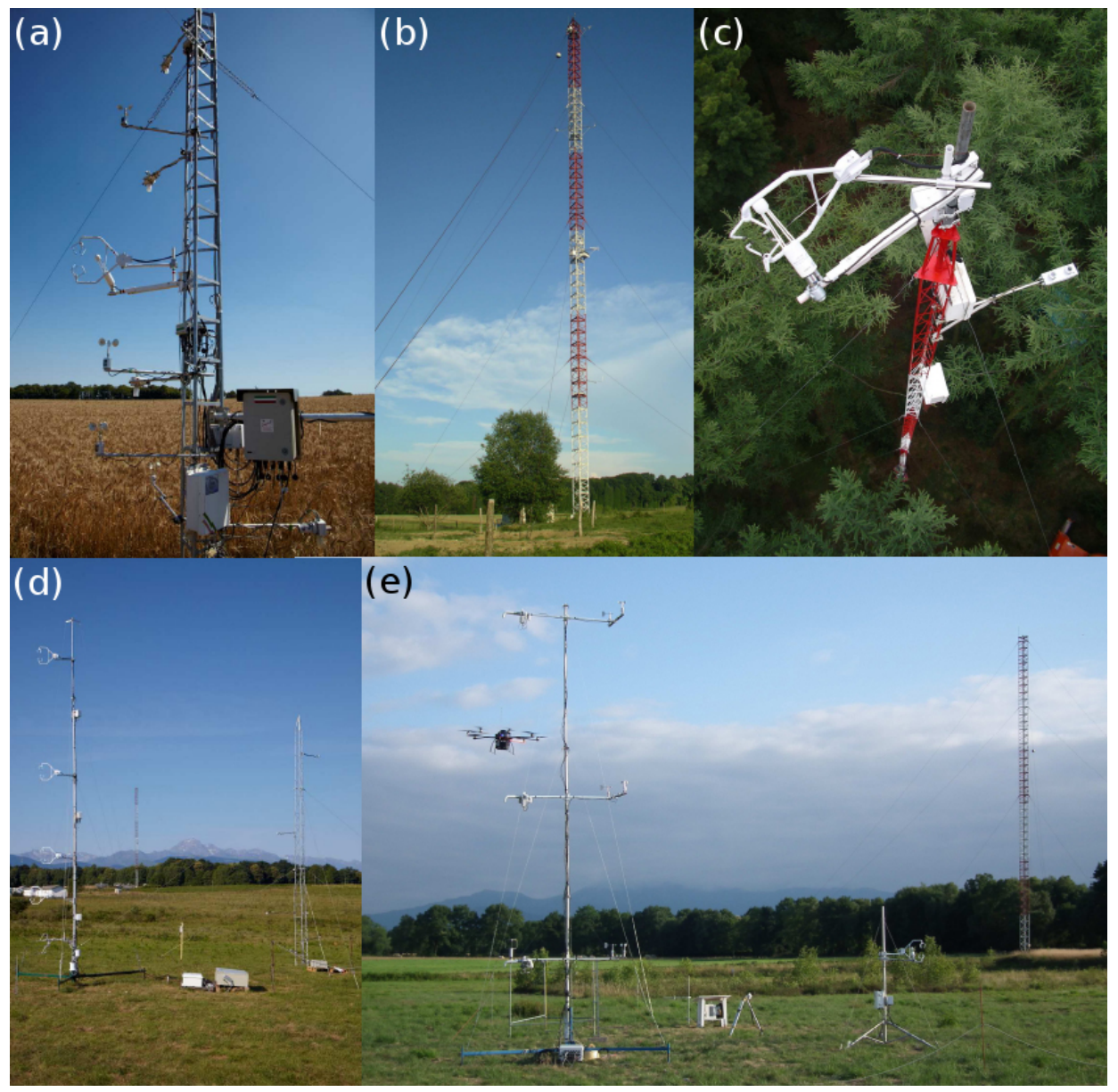

Figure 3. Examples of surface sites during BLLAST: (a) one of the towers at the ss 1 over the wheat, (b) ss 4 with the $60 \mathrm{~m}$ tower, (c) ss 5 over the forest, (d) ss 2 over the prairies, and (e) ss 3 over the micro-scale heterogeneous surface with the ss $460 \mathrm{~m}$ tower behind and the Octocopter flying around. Authors of the pictures: (a), (d) Patrick Dumas; (b), (c) Solène Derrien; (e) Daniel Grenouillet.

limited to low-level flights, ensuring at least $150 \mathrm{~m}$ vertical separation between the lowest flight level of the manned aircraft and the highest RPAS.

\subsubsection{Balloons}

\section{Radiosoundings}

A total of 67 standard MODEM and GRAW radiosondes were launched from site 1 during the IOP days at least 4 times per day at 06:00, 12:00, 18:00 and 24:00 UTC, and assimilated by the Météo-France forecast operational models (Table 2). At site 2, a new technique was used for frequent soundings of the lower troposphere only, during the AT (Legain et al., 2013). Two balloons, with different sizes, attached to the same Vaisala probe, were released. The larger balloon allowed ascent up to about $2 \mathrm{~km}$ height at which time the probe and the smaller balloon were separated from the larger balloon. The smaller balloon brought the probe safely to the ground. A package protecting the probe allowed its reuse after it was recovered. A real-time model predicted the landing area and aided in the decision of when to cut the line that released the probe and the smaller balloon. The time interval between two soundings was between 60 and $90 \mathrm{~min}$. A total of 62 soundings were made with this technique, with $80 \%$ probe retrieval rate (Table 2). Additionally, a few radiosondes were launched simultaneously at the three sites to estimate the divergence at the spatial scale of the plateau on IOPs 6, 7 and 11 .

\section{Tethered balloons}

Three tethered balloons (one at site 1 and two at site 2) operated during all the IOP days (except IOP 4, Table 2), from early afternoon to just after sunset. One balloon was equipped with a newly developed turbulence probe, operated at site 1 (Canut et al., 2014). This probe was composed of a sonic anemometer (Gill Windsonic 3-D), whose oscillations angles were measured by an inertial platform, and a platinum fine wire in a radiation shield for fast air temperature 


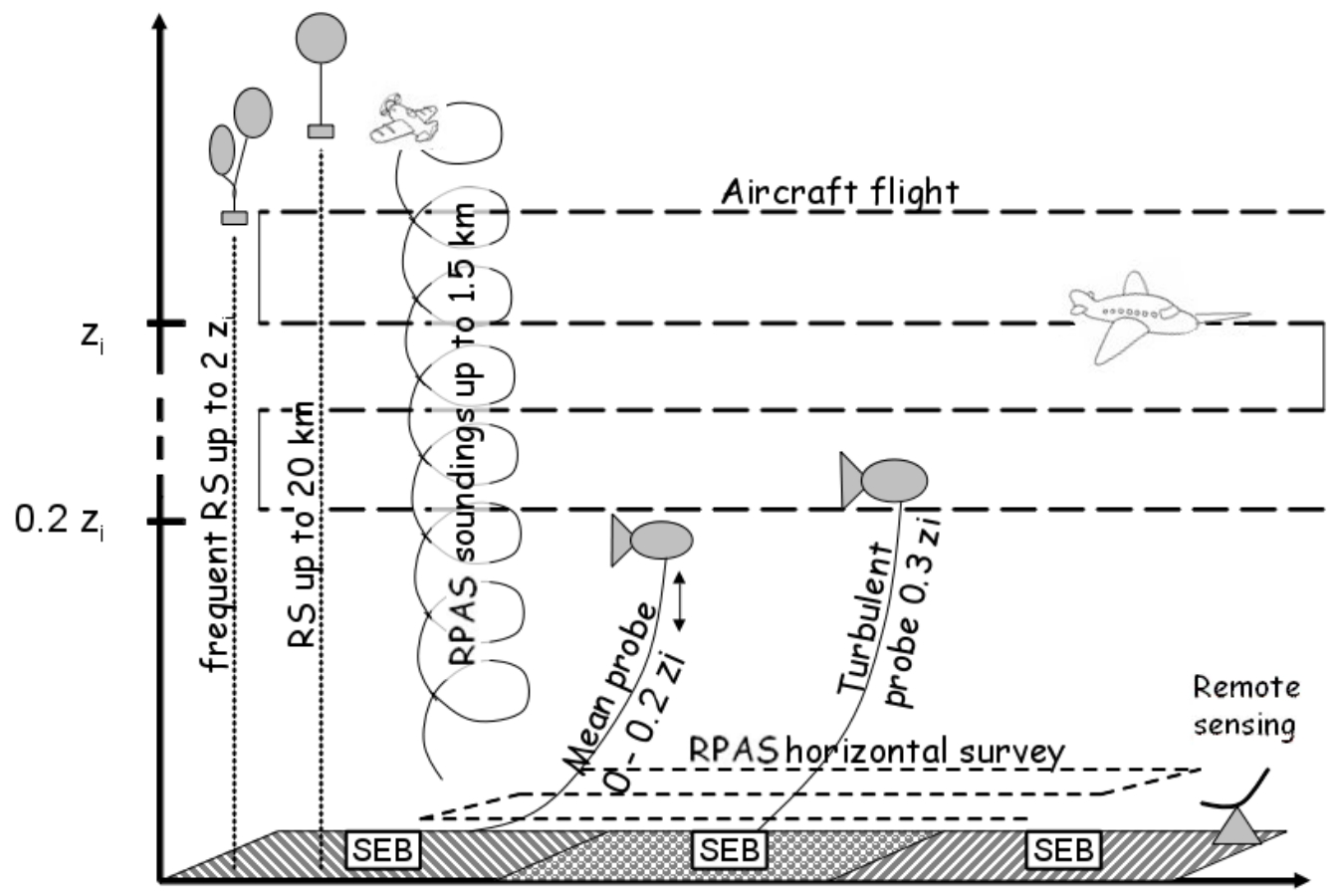

Figure 4. Illustration of the observing strategy during the IOPs. RS = radiosounding, RPAS = remotely piloted aircraft system, $\mathrm{SEB}=$ surface energy balance. Aircraft $=$ Sky Arrow and Piper Aztec.

measurements. The probe was maintained at a given height, as fixed as possible, generally a few hundred metres above the ground, filling the gap of turbulence measurements between the $60 \mathrm{~m}$ tower and the lower leg of the aircraft, and giving a reference for the less validated RPAS measurements.

Two other tethered balloons, which measured mean meteorological variables (temperature, humidity, wind speed and direction) were operated at site 2 , over the maize and the moor fields, with up to five probes at different heights, the four upper ones set at 2,3,5 and $9 \mathrm{~m}$ above the lowest one. The two tethered balloons were performing the same flight pattern: either they were maintained at a fixed low height (the probes were within $15 \mathrm{~m}$ height) or they profiled the first $150 \mathrm{~m}$. The goal was to evaluate the impact of surface heterogeneity on the surface-layer vertical structure.

\subsubsection{Aircraft}

Two aircraft were chosen to participate in BLLAST: the French Piper Aztec from SAFIRE (Saïd et al., 2005), and the Italian Sky Arrow from CNR (Gioli et al., 2006). The Sky Arrow participated from 14 June to 26 June , and the Piper Aztec stayed throughout the campaign (Table 2). Both aircraft measured pressure, temperature, moisture, $\mathrm{CO}_{2}$ concentration and 3-D wind with a spatial resolution of $1 \mathrm{~m}$ for the Sky Arrow and around $3 \mathrm{~m}$ for the Piper Aztec. The detailed instrumentations of the Piper Aztec and the Sky Arrow are given in Tables A3 and A4 of the Appendix, respectively. The aircraft mainly flew in the middle-to-late afternoon. The flight plans were chosen to capture horizontal heterogeneity, vertical structure, the size of the turbulent eddies and their time evolution. Flights generally included stacked level runs in vertical planes and helical profiles. In addition, simpler patterns, such as a large number of passes on a single track to improve statistics, were flown. The two aircraft flew either sequentially to entirely cover the time period from midday to after sunset or together during the same period in order to ensure improved spatial coverage and simultaneous measurements. The levels of the horizontal flight legs were chosen according to the boundary-layer thickness, which was updated with UHF radar or soundings from balloons or RPASs made before take off.

\subsubsection{Remotely piloted aircraft systems}

Table A5 of the Appendix lists the RPASs that flew, and acquired data of interest for BLLAST (see also Table 2 for the number of flights for the main RPASs used).

The small RPAS SUMO was mainly used for frequent profiling up to the top of the TRA and for low-level (typically $60-80 \mathrm{~m}$ above ground) surface temperature mapping surveys (see an example in Fig. 5). Among all the SUMO flights, nearly 50 were performed with a newly integrated turbulence measurement system on board; it is based on a five-hole pressure probe and allows the determination of the 3 -D flow vector in front of the aircraft with a frequency of $100 \mathrm{~Hz}$ (Reuder et al., 2012a, b). 


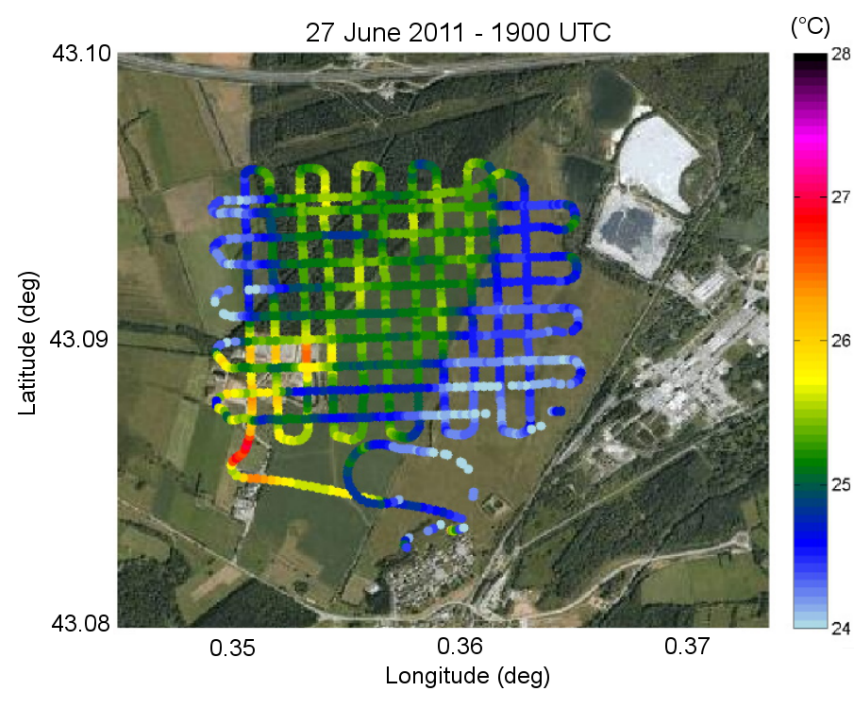

Figure 5. Surface temperature observed by the RPAS SUMO during an exploration survey $60 \mathrm{~m}$ above ground at site 2 on 27 June 2011 (IOP 7). At that time and that day, the forest and the maize had similar temperatures, about $1^{\circ} \mathrm{C}$ warmer than the moor. The hot spot on the bottom left is a bare ground and concrete surface of a waste disposal area (Google-bilder ${ }^{\circledR} 2011$ COWI A/S, DDO, DigitalGlobe, GeoEye, Scankort ${ }^{\circledR}$ Google).

M2AV (Martin et al., 2011) and MASC RPASs are suited for flying kilometre-scale level legs with high-rate measurements of wind components, temperature and humidity fluctuations (van den Kroonenberg et al., 2012). Unfortunately, some technical problems occurred to the MASC, and no data set could be supplied.

The other RPASs only participated during the last two weeks of the field campaign. These adjunct operations were performed as a RPAS test and sensor intercomparison event organized by the European COST Action ES0802 "Unmanned Aerial Systems in Atmospheric Research". In this context, the Octocopter operations were devoted to map the small-scale surface heterogeneities around the ss3 (Fig. 3e). SIRUS, BUSCA, Funjet 1 and 2 systems provided temperature and humidity data on non-IOP days.

\subsection{Forecasts}

During the field campaign, specific forecast output was made available every hour, from two numerical weather prediction (NWP) models of Météo-France: a global model, ARPEGE with a stretched horizontal resolution of about $10 \mathrm{~km}$ over France with a 4D-Var assimilation system, and a limited area non-hydrostatic model, AROME (Seity et al., 2011) with a standard horizontal resolution of $2.5 \mathrm{~km}$. On the vertical, ARPEGE (Courtier and Geleyn, 1988) has about 11 levels within the first kilometre (first level at $37 \mathrm{~m}$ a.g.l.), and AROME has about 15 levels (first level at $22 \mathrm{~m}$ ).
There were two objectives in the AROME and ARPEGE forecast model output: (1) to help in the planning of the intensive observations during the field experiment and (2) to evaluate the behaviour of the two models, especially during the afternoon transition (Couvreux et al., 2014).

\subsection{Educational aspects}

Educational activities enabled undergraduate students from Germany and the Netherlands to participate in the field experiment thanks to the practical training programs of Bonn and Wageningen universities that were integrated into the experimental plans. Additionally, several students also took a course on airborne atmospheric measurements and participated in BLLAST flights through the two associated EUFAR (European Facility for Airborne Research) projects BLLATE-1 and BLLATE-2. Several early stage researchers could participate in the campaign via the short-term scientific mission (STSM) scheme provided by the COST Action ES0802.

\subsection{Data set}

During the field experiment, a field catalog (http://boc.sedoo. fr) supplied quick looks of the continuous measurements and IOP observations, satellite images, reports, model forecasts and analyses, which are still available. The BLLAST web site (http://bllast.sedoo.fr) describes the project and contains the documentation, presentations and field catalog, and also gives access to the observational and modelling data and metadata. The data set was reserved for BLLAST participants until 2014, and has been opened to the scientific community since then. We encourage people to contact instrument principal investigators whenever using one of the BLLAST data sets.

\section{Potential of BLLAST data set}

Here, we illustrate the potential of the observations made during the field experiment to address the issues raised by the AT and ET. We first show an overview of the conditions that were encountered during the field experiment, followed by a general description of some characteristics of the AT, including the turbulence kinetic energy decay and the evolution of turbulence length scales.

\subsection{Overview}

\subsubsection{Meteorological conditions}

Figures 6 and 7 present series of $24 \mathrm{~h}$ sequences for the 12 IOPs, from 14 June to 5 July 2011 of the solar irradiance, the wind speed and direction, the sensible and latent heat flux over different surfaces, and the evolution of $Z_{i}$ (PBL depth) estimates from several sources and by the use of different criteria. 
Table 2. Intensive observations made by the two aircraft (number of flights (FL) and hours), Remotely piloted aircraft system (RPAS) (number of flights), radiosoundings (RS) (number of launches), and tethered balloons (TB) (duration).

\begin{tabular}{|c|c|c|c|c|c|c|c|c|c|c|}
\hline & \multicolumn{2}{|c|}{ AIRCRAFT } & \multicolumn{3}{|c|}{ RPAS } & \multicolumn{3}{|c|}{$\mathrm{RS}$} & \multicolumn{2}{|r|}{$\mathrm{TB}$} \\
\hline & $\begin{array}{l}\text { Sky } \\
\text { Arrow }\end{array}$ & $\begin{array}{l}\text { Piper } \\
\text { Aztec }\end{array}$ & SUMO & $\mathrm{M} 2 \mathrm{AV}$ & Octocopter & Site1 & Site2 & Site3 & Site 1 & $\begin{array}{c}\text { Site } 2 \\
\text { Moor/maize }\end{array}$ \\
\hline $\begin{array}{l}\text { IOP00 } \\
14 / 06 / 2011\end{array}$ & $\begin{array}{l}2 \mathrm{FL} \\
(2 \mathrm{~h})\end{array}$ & & $3 \mathrm{FL}$ & & & 8 & 1 & & & \\
\hline $\begin{array}{l}\text { IOP01 } \\
15 / 06 / 2011\end{array}$ & $\begin{array}{l}2 \mathrm{FL} \\
(4 \mathrm{~h})\end{array}$ & $\begin{array}{l}2 \mathrm{FL} \\
(3 \mathrm{~h})\end{array}$ & $21 \mathrm{FL}$ & & & 7 & 6 & & $8 \mathrm{~h}$ & $6 \mathrm{~h} / 5 \mathrm{~h}$ \\
\hline $\begin{array}{l}\text { IOP02 } \\
\text { 19/06/2011 }\end{array}$ & $\begin{array}{l}2 \mathrm{FL} \\
(4 \mathrm{~h})\end{array}$ & $\begin{array}{l}2 \mathrm{FL} \\
(4 \mathrm{~h})\end{array}$ & $28 \mathrm{FL}$ & & & 4 & 8 & & $8 \mathrm{~h}$ & $6 \mathrm{~h} / 4 \mathrm{~h}$ \\
\hline $\begin{array}{l}\text { IOP03 } \\
\text { 20/06/2011 }\end{array}$ & $\begin{array}{l}3 \mathrm{FL} \\
(5 \mathrm{~h})\end{array}$ & $\begin{array}{l}2 \mathrm{FL} \\
(4 \mathrm{~h})\end{array}$ & $23 \mathrm{FL}$ & & & 4 & 7 & & $8 \mathrm{~h}$ & $5 \mathrm{~h} / 4 \mathrm{~h}$ \\
\hline $\begin{array}{l}\text { IOP04 } \\
24 / 06 / 2011\end{array}$ & $\begin{array}{l}2 \mathrm{FL} \\
(4 \mathrm{~h})\end{array}$ & & $12 \mathrm{FL}$ & & & 4 & & & & \\
\hline $\begin{array}{l}\text { IOP05 } \\
25 / 06 / 2011\end{array}$ & $\begin{array}{l}3 \mathrm{FL} \\
(4 \mathrm{~h})\end{array}$ & $\begin{array}{l}3 \mathrm{FL} \\
(5 \mathrm{~h})\end{array}$ & $19 \mathrm{FL}$ & & & 4 & 8 & & $8 \mathrm{~h}$ & $3 \mathrm{~h} / 6 \mathrm{~h}$ \\
\hline $\begin{array}{l}\text { IOP06 } \\
26 / 06 / 2011\end{array}$ & $\begin{array}{l}2 \mathrm{FL} \\
(4 \mathrm{~h})\end{array}$ & $\begin{array}{l}2 \mathrm{FL} \\
(4 \mathrm{~h})\end{array}$ & $23 \mathrm{FL}$ & & & 6 & 6 & 1 & $8 \mathrm{~h}$ & $6 \mathrm{~h} / 6 \mathrm{~h}$ \\
\hline $\begin{array}{l}\text { IOP07 } \\
27 / 06 / 2011\end{array}$ & & $\begin{array}{l}2 \mathrm{FL} \\
(2 \mathrm{~h})\end{array}$ & $35 \mathrm{FL}$ & & & 6 & 2 & 2 & $8 \mathrm{~h}$ & $6 \mathrm{~h} / 5 \mathrm{~h}$ \\
\hline $\begin{array}{l}\text { IOP08 } \\
30 / 06 / 2011\end{array}$ & & $\begin{array}{c}2 \mathrm{FL} \\
(4.5 \mathrm{~h})\end{array}$ & $17 \mathrm{FL}$ & $2 \mathrm{FL}$ & & 3 & & & $8 \mathrm{~h}$ & $5 \mathrm{~h} / 4 \mathrm{~h}$ \\
\hline $\begin{array}{l}\text { IOP09 } \\
1 / 07 / 2011\end{array}$ & & $\begin{array}{c}2 \mathrm{FL} \\
(4.5 \mathrm{~h})\end{array}$ & $11 \mathrm{FL}$ & $2 \mathrm{FL}$ & $10 \mathrm{FL}$ & 7 & 8 & & $8 \mathrm{~h}$ & $7 \mathrm{~h} / 7 \mathrm{~h}$ \\
\hline $\begin{array}{l}\text { IOP10 } \\
2 / 07 / 2011\end{array}$ & & $\begin{array}{l}2 \mathrm{FL} \\
(4 \mathrm{~h})\end{array}$ & $12 \mathrm{FL}$ & $4 \mathrm{FL}$ & $8 \mathrm{FL}$ & 6 & 8 & & $8 \mathrm{~h}$ & $5 \mathrm{~h} / 5 \mathrm{~h}$ \\
\hline $\begin{array}{l}\text { IOP11 } \\
5 / 07 / 2011\end{array}$ & & $\begin{array}{l}3 \mathrm{FL} \\
(6 \mathrm{~h})\end{array}$ & $14 \mathrm{FL}$ & $5 \mathrm{FL}$ & $14 \mathrm{FL}$ & 8 & 8 & 3 & $8 \mathrm{~h}$ & $6 \mathrm{~h} / 4 \mathrm{~h}$ \\
\hline Sub-Total & $\begin{array}{l}16 \mathrm{FL} \\
(27 \mathrm{~h})\end{array}$ & $\begin{array}{l}22 \mathrm{FL} \\
(41 \mathrm{~h})\end{array}$ & $218 \mathrm{FL}$ & $13 \mathrm{FL}$ & $22 \mathrm{FL}$ & 67 & 62 & 6 & $80 \mathrm{~h}$ & $55 \mathrm{~h} / 50 \mathrm{~h}$ \\
\hline Total & $\begin{array}{r}38 \mathrm{f} \\
6\end{array}$ & $\begin{array}{l}\text { ghts } \\
\text { h }\end{array}$ & & $260 \mathrm{flig}$ & & & 5 launc & & & $185 \mathrm{~h}$ \\
\hline
\end{tabular}

In contrary to the other days which were almost cloud free, 14, 15, 24 and 30 June were cloudy (Fig. 6a), either with fair weather clouds, or starting with a stratocumulus cloud in the morning which broke into fair weather cumuli in the afternoon. Most of the time, those clouds were due to the rain and moisture advected into the area by frontal systems on previous days.

The wind at the surface was generally weak during the field campaign, with $10 \mathrm{~min}$ average values below $4 \mathrm{~m} \mathrm{~s}^{-1}$ and daily averages $<2 \mathrm{~m} \mathrm{~s}^{-1}$ for most of the IOPs (Fig. 6b). A typical nocturnal southerly downslope wind was frequently observed (Fig. 6c) and, during the day, either north-easterly upslope winds (14, 15, 19, 20 and 24 June and 1, 2 and 5 July, that are IOPs $0,1,2,3,4,9,10$ and 11 , respectively), or weak westerly winds on 30 June (IOP 8). In weak-wind synoptic conditions, which is the situation of most of the BLLAST IOP days, the diurnal cycle that is imposed by the presence of nearby mountains generates very calm conditions during the late afternoon and evening as revealed in Fig. 6b, favourable for the study of the AT. Of course, the diurnal cycle of the low-level wind and the associated wind reversal needs to be considered with the transition processes, as well as the link between the mesoscale circulation and the PBL growth and evolution. Note that the wind reversal typically occurs around 20:00 UTC, about two hours after the buoyancy flux gets to zero. 
(a)

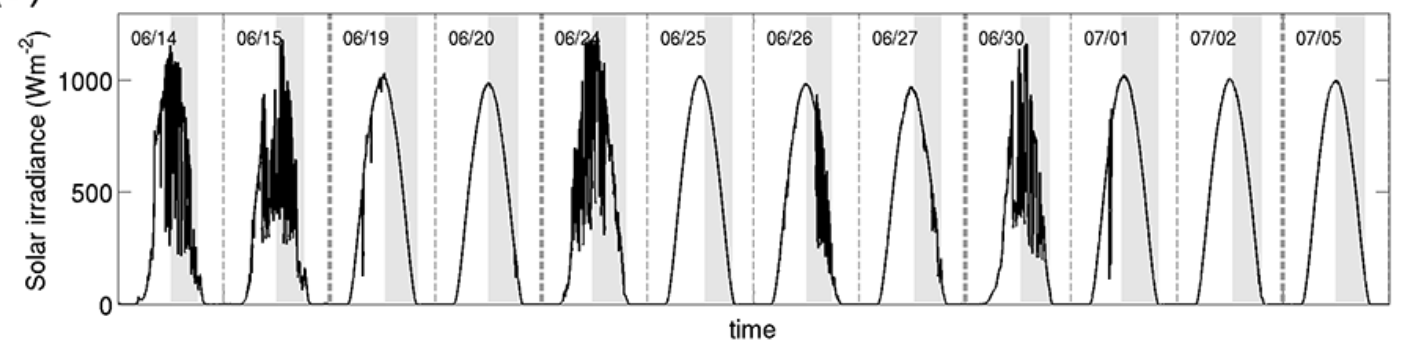

(b)

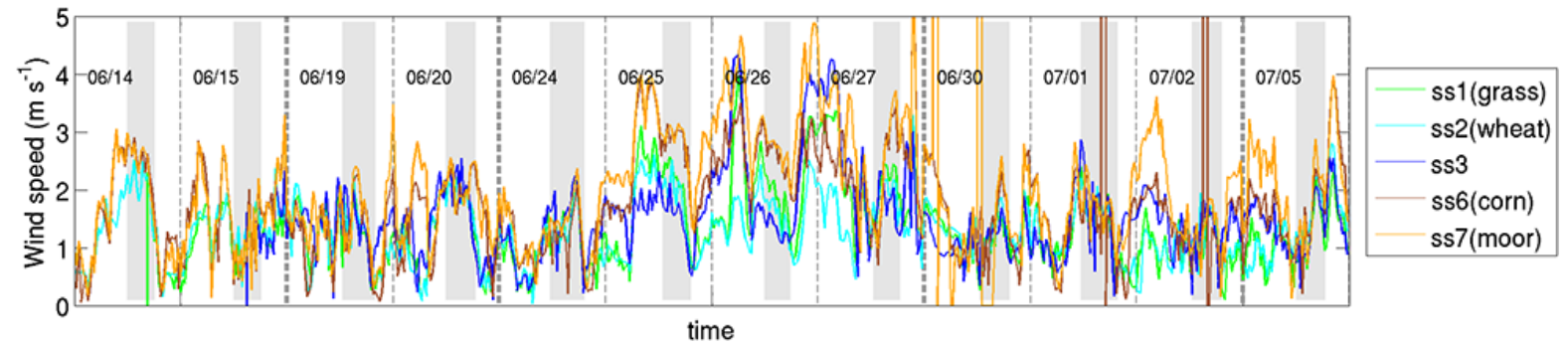

(c)

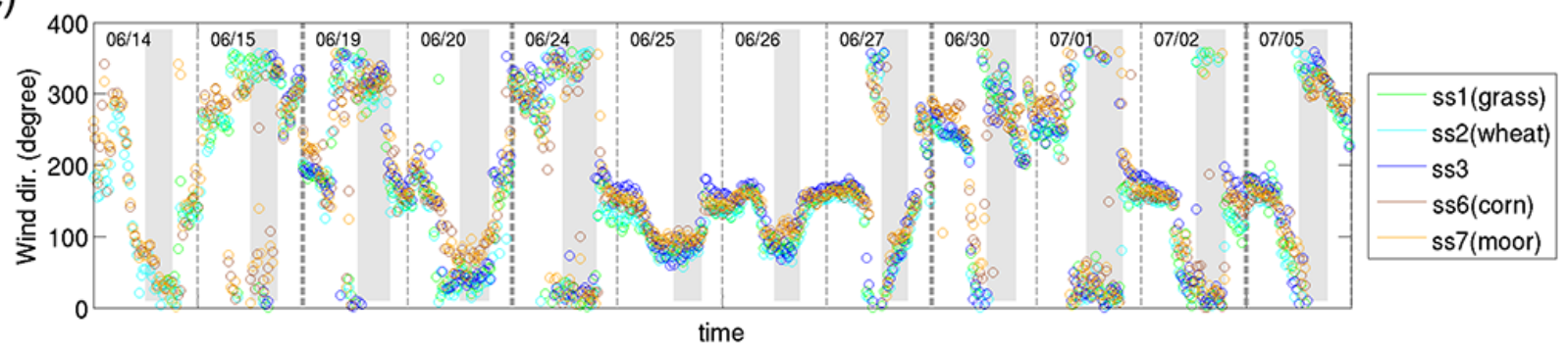

Figure 6. Time series of (a) solar irradiance over the moor surface at site 2, (b) wind speed and (c) wind direction, measured over several surfaces at the different sites (see Fig. 2). The shaded areas mark the AT period.

Surface sensible heat flux at midday during the IOPs ranged between $100 \mathrm{~W} \mathrm{~m}^{-2}$ over grass and moor and $400 \mathrm{~W} \mathrm{~m}^{-2}$ over the forest (Fig. 7a). At $60 \mathrm{~m}$ height, intermediate values were measured, which is consistent with the fact that at this height, the flux resulted from contributions of several types of vegetated surfaces within the flux footprint area. Contrary to the sensible heat flux, the latent heat fluxes were much more similar between the various surfaces (Fig. 7b), reaching around $350 \mathrm{~W} \mathrm{~m}^{-2}$ at midday for all IOPs and leading to different evaporative fraction (i.e. the ratio of latent heat flux to the sum of latent heat flux and sensible heat flux) values according to the vegetation. The three IOPs 5, 6 and 7 (25-27 June) represent a particular period during the BLLAST experiment since they are characterized by a surface wind slightly higher than that for the other IOPs (daily average of $3 \mathrm{~m} \mathrm{~s}^{-1}$ ) and coming from the east. This less typical wind was due to the presence of a low pressure area in the lower troposphere over the Gulf of Lion in the Mediterranean Sea. Warm air occupied the low troposphere. It led to very small sensible heat fluxes (Fig. 7a), which were compensated by increased latent heat flux during those days (Fig. 7b).
Figure 7c shows an overview of the PBL growth during the IOPs over the entire field campaign. Estimates of $Z_{i}$ were made from various observational sources, based on the following criteria: $(\mathrm{C} 1)$ the height where the virtual potential temperature $\left(\theta_{\mathrm{v}}\right)$ exceeds a certain threshold based on the value of $\theta_{\mathrm{v}}$ at the surface, (C2) the height of maximum relative humidity, (C3) the height of maximum first derivative of the potential temperature, (C4) the height of minimum first derivative of specific humidity, (C5) the height of largest gradient of aerosol backscatter (from wavelet analysis) and (C6) the height of maximum air refractive index structure coefficient (local maximum, with conditions on time continuity and consistency with the previous criterion). Criteria (C1), (C2), (C3) and (C4) were used for radiosonde and SUMO data, criterion (C5) for site 1 aerosol lidar data and criterion (C6) for site 1 UHF wind profiler data. Figure $7 \mathrm{c}$ only shows the criteria $(\mathrm{C} 1)$ and $(\mathrm{C} 2)$ for radiosonde and SUMO data, and criteria (C5) and (C6) for remote sensing. The results first show that the PBL was usually around $1000 \mathrm{~m}$ and did not reach more than $1400 \mathrm{~m}$ over the campaign. It was particularly shallow during the hot period mentioned above on 25, 26 and 27 June, due to smaller sensible heat flux. The 
(a)

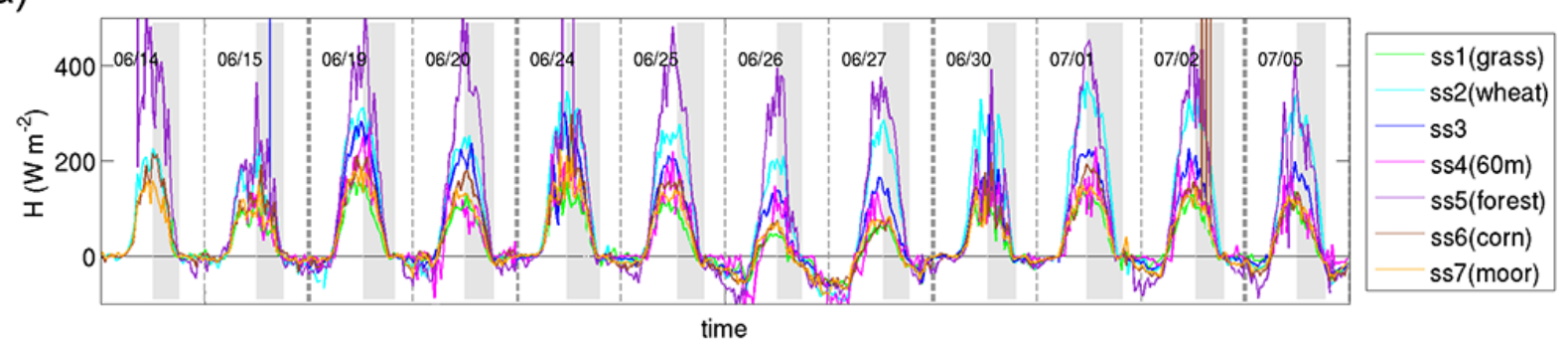

(b)

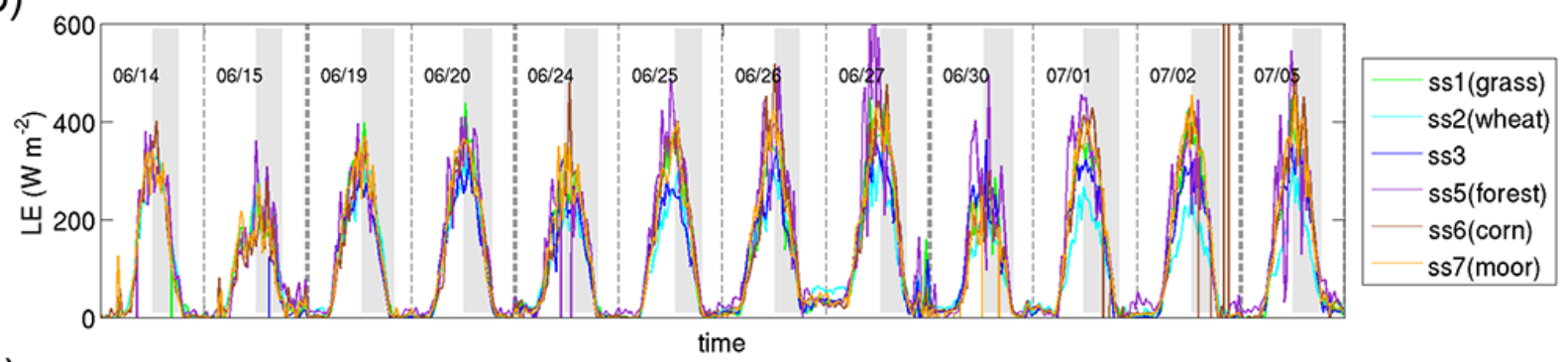

(c)

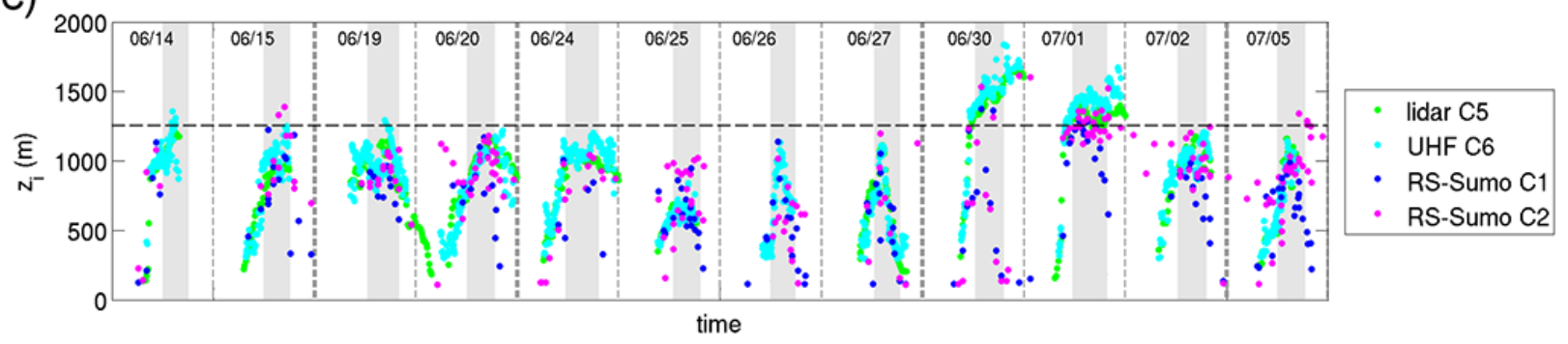

Figure 7. Time series of (a) sensible heat flux $H$, (b) latent heat flux measured over several surfaces at the different sites (see Fig. 2) and (c) estimates of $Z_{i}$ from various measurements, using criteria (C1) in dark blue, (C2) in pink, (C5) in green and (C6) in bright blue defined in the text. The shaded areas mark the AT period. In (c), the horizontal dashed line indicates $Z_{i}=1200 \mathrm{~m}$.

morning growth rate was quite variable from day to day, but most of the time monotonic and smooth. The different estimates are in general consistent, but interestingly depart from each other on some specific days in the late afternoon. In those cases, the mixed-layer depth detected from the thermodynamical criteria decreased with time in the late afternoon, while the residual top inversion and aerosol layer remained approximately the same (19, 24, 30 June and 1,2, 5 July).

This overview shows the variety of fair-weather conditions encountered during the IOPs. The AT period as defined in section 1 is indicated by the shaded areas for each day. Since it depends on local surface characteristics, the longest period is considered here: from the first time when the surface sensible heat flux is maximum on any surface, to the last time of its changing sign over any surface. It is interesting to see that the sensible heat flux may start to decrease (and the AT to start) before the downward solar radiation has reached its maximum (Fig. 7a), with still growing PBL for several hours before subsiding.
Also note that the sunrise is around 04:20 UTC (06:20 LT) during this period and at this area, and the sunset around 19:40 UTC (21:40 LT).

\subsubsection{Afternoon transition duration}

Here, we adopt the same definitions as Nadeau et al. (2011): the AT starts as soon as the surface sensible heat flux begins to decrease and ends when it becomes negative. Figure 8 quantifies the duration of the afternoon transition (AT) as a function of the time at which the surface sensible heat flux starts to decrease, for all IOPs and several surface covers. In agreement with Grimsdell and Angevine (2002), we find that the AT can last several hours and have an early start. This is enhanced here by the singular hot period during IOPs 5, 6 and 7, which is characterized by the shortest AT durations $(3 \mathrm{~h})$, because the sensible heat flux changed its sign much earlier. Over grass and moor, characterized by larger evaporative fractions, the maximum of sensible heat flux can be reached early in the day, with AT durations spreading from about $3-4 \mathrm{~h}$ to about $7-8 \mathrm{~h}$. In contrary, over forest and wheat, this maximum is normally reached around 12:00 UTC, and 


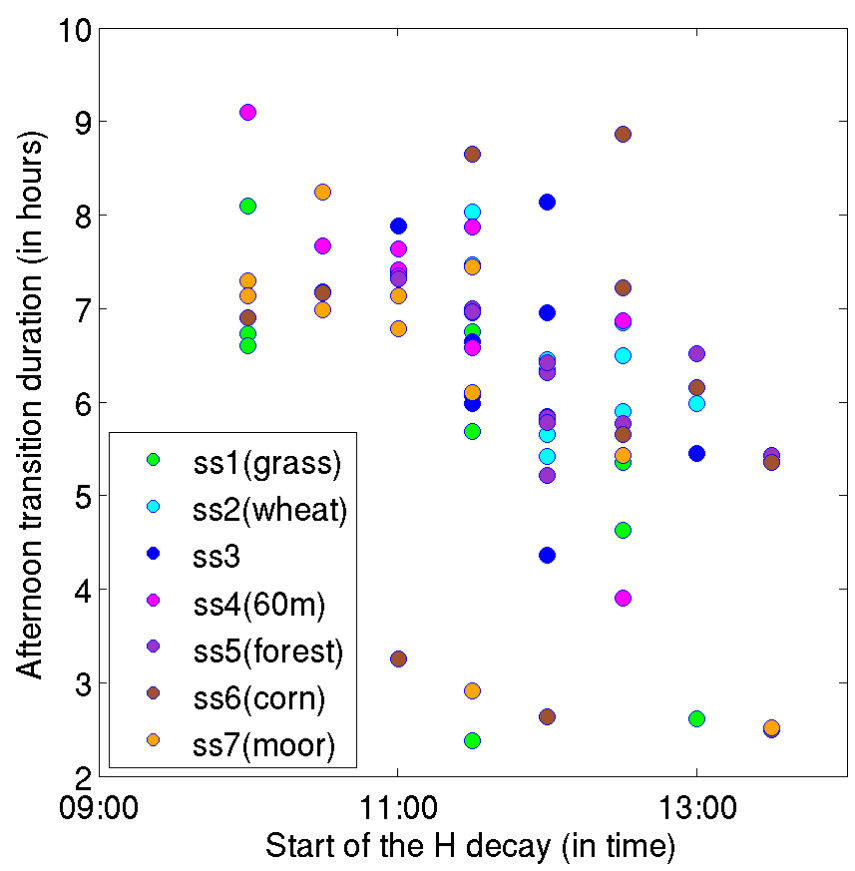

Figure 8. Duration of the afternoon transition as a function of the starting time of the sensible heat flux decay over several surfaces and for all IOP days and sites (colours).

the AT lasts for about $6 \mathrm{~h}$. Therefore, this figure shows how variable the start and the duration of the AT can be according to the vegetation coverage and the meteorological conditions. It is one aim of BLLAST to further address the role of the surface heterogeneity in the AT. The very early start (around 10:00 UTC) over some particular vegetation even reveals the difficulty to correctly name and define this period, which, however, might remain quasi-steady for several hours if the boundary layer is able to keep the equilibrium, in spite of the decaying turbulent energy and change in the relative contributions of the processes (buoyancy, shear, transport and pressure forces).

Note that using buoyancy flux rather than sensible heat flux for the definition of the AT period does not change significantly the overall result (not shown). This is consistent with the larger differences found in sensible heat flux than in latent heat flux from one surface to the other (soil moisture is not a constraint during BLLAST). When the period is defined with buoyancy flux, the start time is delayed for $15 \mathrm{~min}$ on average and the time of zero flux is delayed for around $30 \mathrm{~min}$ on average, with a longer delay during the hot period.

\subsubsection{Classification of the diurnal evolution of the PBL depth}

The variety of forcings partly addressed in Sect. 2.2.3, including local processes, radiative forcing, large-scale subsidence and advection, etc., can lead to different PBL growth and evolution, according to the day.

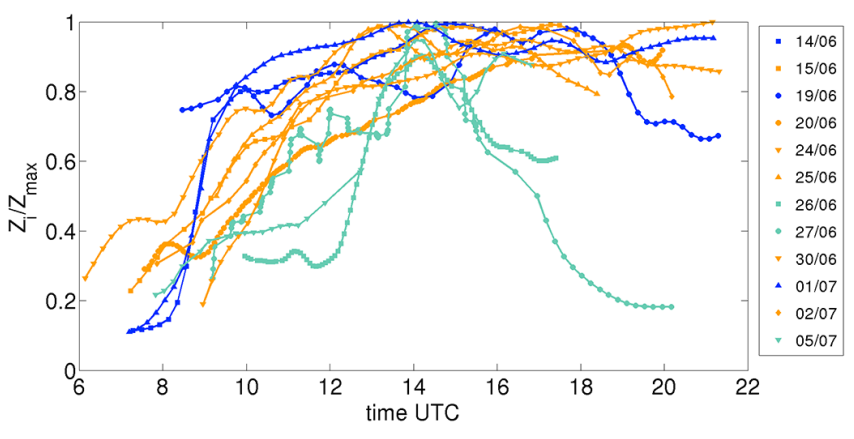

Figure 9. Evolution of the CBL top, defined here as height of the top inversion $Z_{i}$, for all IOPs. $Z_{i}$ is divided by its maximum value reached the same day for day-to-day comparison, and has been smoothed with a $1 \mathrm{~h}$ moving average. The estimates are made from lidar backscatter at site 1, except for day 26 June when the UHF radar estimates were used instead, due to missing data. One symbol is used per IOP. Three sets of cases have been identified: (blue) rapid growth and levelling inversion in late afternoon, (orange) more typical growth and levelling inversion and (green) slower growth and rapidly decreasing top inversion in late afternoon.

Figure 9 shows the non-dimensional PBL growth of all IOP days. The capping inversion of the convective boundary layer estimated by UHF radar or lidar is normalized here by the maximum height reached over the day. We found three ensembles for the 12 cases: (1) frequent cases with intermediate growth rates and a slightly descending summit inversion during the AT (15, 20, 24, 25, 30 June, 2 July); (2) cases of rapid growth of the morning CBL, with levelling inversion during the AT (14 June, 19 June and 1 July); (3) cases with slow growth of the CBL during the morning and rapid decrease of the inversion during the AT (cases of 26 June, 27 June and 5 July). For the cases of the first "typical" class, the growth of the CBL lasts around $4 \mathrm{~h}$, while it lasts about $1 \mathrm{~h}$ $30 \mathrm{~min}$ in the second class, and around 5 or $6 \mathrm{~h}$ in the third class.

The evolution of the vertical structure observed in each of the three classes defined above is shown in more detail in Figs. 10 and 11, based on three examples. Figure 10 shows a time-height cross section of the TKE dissipation rate that is estimated from the UHF wind profiler Doppler spectral width (Jacoby-Koaly et al., 2002) for 24 June, 1 July and 26 June, which are examples of the above-mentioned (1), (2) and (3) cases, respectively. The capping inversion is superimposed. Figure 11 presents the vertical profiles of the potential temperature obtained from a selection of radiosoundings (standard radiosoundings or afternoon frequent radiosoundings) for the three same days. For the two first examples, Fig. 10 shows a separation during the AT between the top of the mixed turbulent layer and the capping inversion. This is also consistent with observations reported by Grimsdell and Angevine (2002) and with Angevine (2008) stating that the decaying turbulent layer gets decoupled from the inversion as time goes by. We especially observe this for the typical 


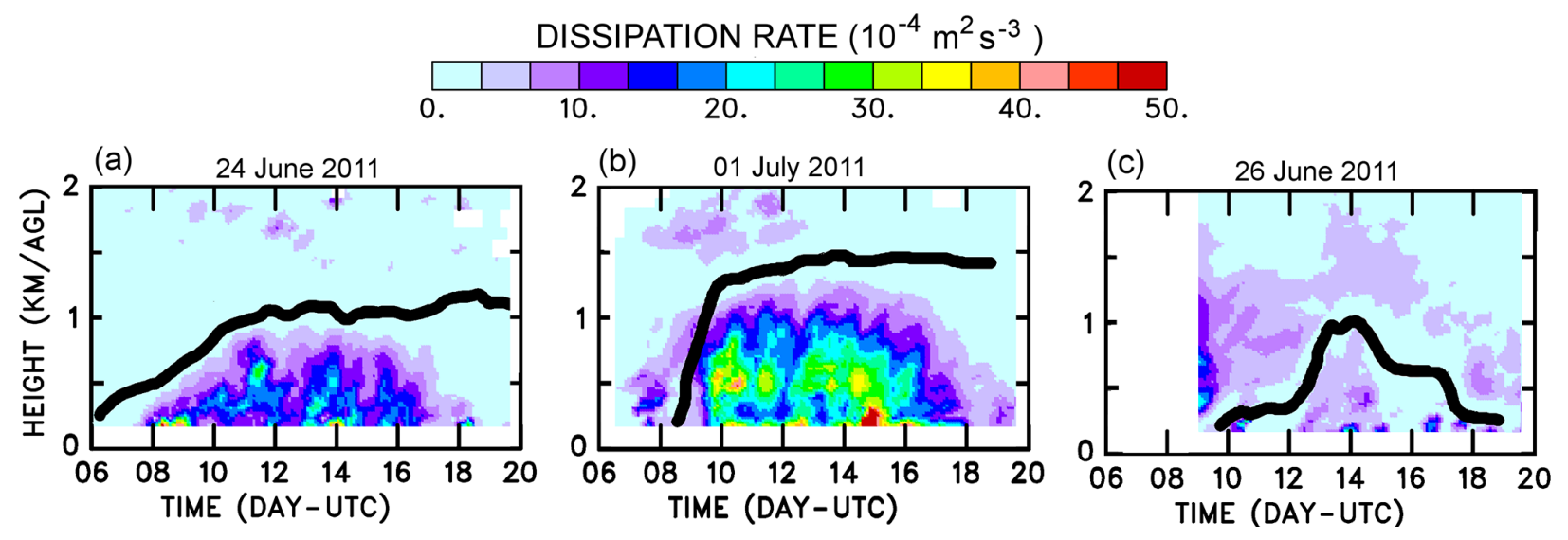

Figure 10. Time-height section of TKE dissipation rate estimated from UHF wind profiler during (a) 24 June, (b) 1 July and (c) 26 June 2011. The evolution of the CBL top inversion (deduced from local maximum of the refractive index structure parameter) is indicated by the black thick line.
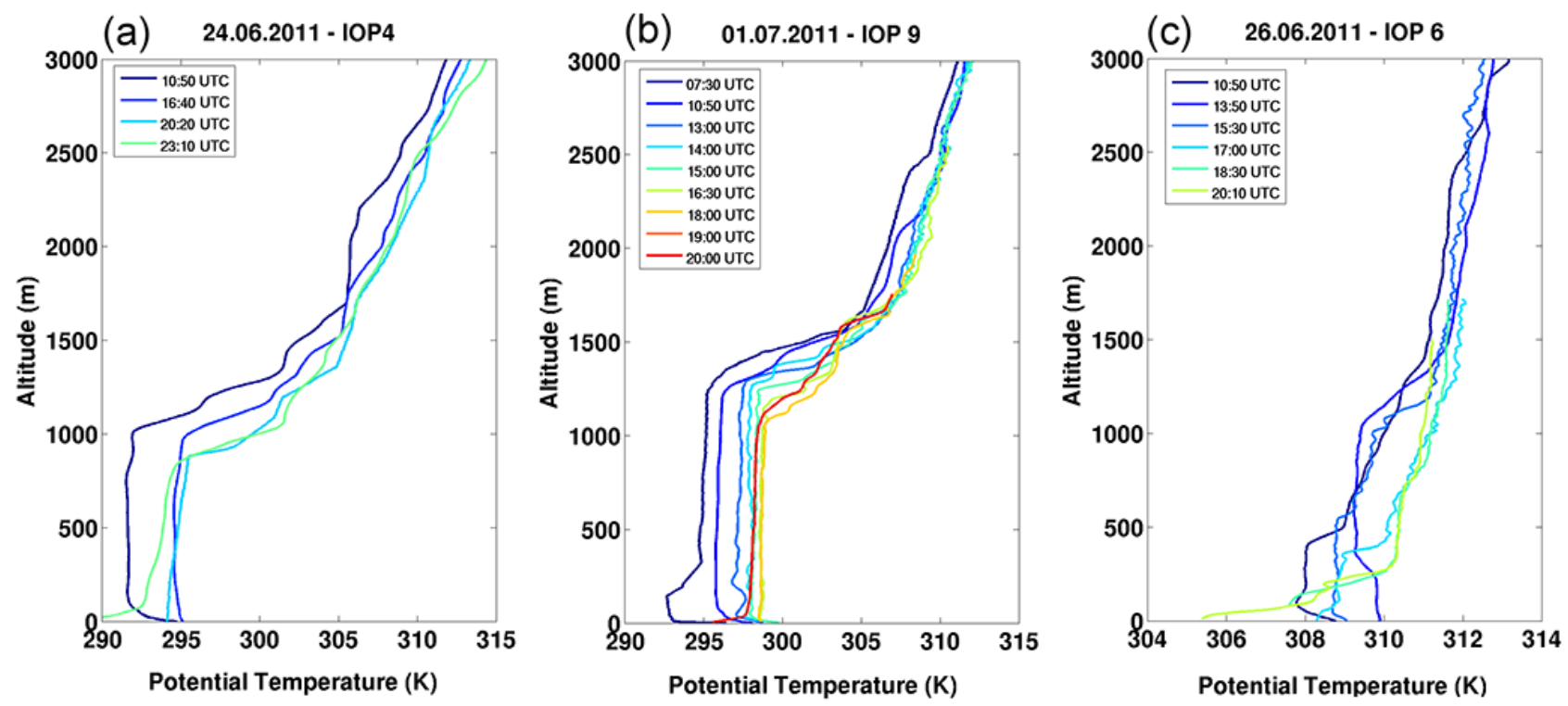

Figure 11. Vertical profiles of potential temperature measured by radiosondes on (a) 24 June, (b) 1 July and (c) 26 June 2011 . The launching time is indicated in the top-left corner of each panel.

case (1) (Fig. 10a) and the rapid growth case (2) (Fig. 10b), with a top-down decrease of the TKE dissipation rate that starts between 14:00 and 16:00 UTC without descent of the inversion height. This can also be interpreted as a decrease of the thickness of the turbulent layer as assessed by TKE dissipation rate. A more rapid top-down decay of the dissipation rate is observed between 16:00 and 18:00 UTC. For the case (3), a sharp decrease of the mixed turbulent layer is accompanied by a marked descent of the inversion in the first phase of the AT.

The profiles in Fig. 11 show that for 1 July (Fig. 11b), the rapid growth of the morning CBL is due to the presence of a residual layer that remained close to neutral (as seen for example by Freedman and Fitzjarrald, 2001). This resid- ual layer is well seen in the profile of 07:20 UTC, overlying the current mixed layer of $200 \mathrm{~m}$ depth. Once the mixing allowed the potential temperature to reach that of the residual layer above, the CBL deepened rapidly and integrated this residual layer in the mixed layer, as seen at 11:00 UTC. As shown in Fig. 10b, this day had significant turbulence (with also large TKE dissipation rates), and relatively deep CBL (Fig. 7c). The frequent radiosoundings reveal the presence of large-scale subsidence above the CBL top. Blay-Carreras et al. (2014a) have studied this case in detail, and especially analyzed the impact of the residual layer and of the presence of subsidence in the evolution of the CBL. During the last part of the AT, the CBL keeps warming until 18:00 UTC with a slight descent of the CBL top. At 18:00 UTC, $1 \mathrm{~h} 40 \mathrm{~min}$ 
before sunset, the profile is still very well mixed but just beginning to stabilize. At 19:00 UTC, the temperature has decreased and the surface layer has started to stabilize.

The example of 26 June in Figs. 10c and 11c reveals a very limited growth of the CBL that hot day, with very light turbulence. Subsidence of warm air during this period made it very difficult for the CBL to grow, with hardly any sensible heat flux at the surface, small super-adiabatism, as well as less shear at the CBL top than other days. The small temperature jump at the top may reveal strong subsidence that is confirmed by estimates from the forecast models. This is found for the three days of case (3). The decay of TKE dissipation rate is more synchronized with the descent of the CBL top in the last part of the AT. Compared to 1 July, the stabilization of the surface layer started earlier (at 17:00 UTC), as shown by the sounding in Fig. 11c.

The example of 24 June (Figs. 10a and 11a) for the more typical case (1) presents several aspects similar to the 1 July, but with a less rapid growth of the CBL and smaller TKE dissipation rates. 25 June, in the same group (1), is studied in detail by Piertersen et al. (2014) and found as an example of "prototype" CBL.

This overview has shown the various types of boundary layers that were probed during BLLAST. We have shown that the second class of rapid growth cases corresponds to wellmixed residual layers and a likely significant subsidence that prevents further growing of the CBL after its rapid morning rise. We have also identified a period of hot subsiding air mass, which lead to very small sensible heat flux and large evaporative fraction, weak turbulence and poor CBL growth, that corresponds to the third case. The stratification of the early morning or night before is essential in the observed evolution of the daytime CBL. The mesoscale forcing and mountain-induced circulations also impact on the CBL growth via subsidence or advection. For example, the largescale subsidence may show a diurnal cycle, as shown by previous studies (Whiteman, 1990) and confirmed by preliminary analyses of BLLAST data set on this issue. Similar results were found by Jiménez and Cuxart (2014a) based on a mesoscale simulation in the northern Pyrénées under similar conditions (at the end of June 2010). Several studies have started to address those issues and take account of the large-scale forcing in BLLAST (Blay-Carreras et al., 2013; Pietersen et al., 2014).

The panel of various conditions shown in this subsection allowed us to define several so-called "golden days" (like 1 July, 25 June and 20 June; see Blay-Carreras et al., 2014a; Pietersen et al., 2014; Darbieu et al., 2014), which were selected to evaluate or intercompare a complete hierarchy of numerical models, i.e. forecast, mesoscale and large-eddy simulation models (not addressed in this article - Jiménez et al., 2014; Angevine et al., 2014; Jiménez and Cuxart, 2014b) or use one or the other model for a better understanding of specific key processes.

\subsection{Turbulence decay}

Turbulence decay is one of the main foci of the analyses of BLLAST data. Here we give examples of this decay observed at the surface and in the boundary layer above and illustrate how BLLAST data set enables to address the questions raised in Sect. 2.2.1.

Figure 12a presents the turbulent kinetic energy decay observed from surface stations over five different surfaces and from aircraft, on all IOP days. RPASs and the turbulence probe carried by the tethered balloon at site 1 also measured turbulence at heights that are complementary to those probed by the aircraft and by the instrumented towers (not shown). The BLLAST data set therefore provides a diverse combination of estimates for the study of turbulence decay.

Figure 12a shows the two regimes of the decay that were presented by Nadeau et al. (2011): an initial slow decay (starting around 15:00 UTC in Fig. 12a) followed by an abrupt decay (after 17:00 UTC). Based on this gradual afternoon decay, one can see the interest of considering the entire AT (which may start very early as seen before), when studying the AT TKE decay, in order to start from the initial conditions of a fully convective and mixed boundary layer. The change from a slow to a more abrupt decay is generally found when the surface flux decrease rate is maximum. Note that the increase of TKE seen with surface measurements at the evening transition for some cases is due to the onset of the downslope wind after the mountain-plain circulation has reversed. Also note that the change of TKE with height is put into evidence by the different flight levels and surface measurements, with larger TKE closer to the interfaces (surface and CBL top) than in the middle of the CBL.

The decay in Fig. 12a is purposely shown with no scaling. The usual representation of the decay consists in a logarithmic diagram of the turbulence kinetic energy integrated over height (for LES studies especially) or observed at surface, divided by the square of the convective velocity scale at the initial time (midday) before the decay. Time is also normalized by the midday convective timescale in those previous studies (e.g. Sorbjan, 1997; Nadeau et al., 2011), that is there is no effective normalization by a scaling factor that would evolve with time as the surface flux decreases. Using this usual technique with our data set actually increase the scatter of the results, especially due to the contribution of the timescaling. However, we show in Fig. 12b the surface TKE normalized by either the convective velocity scale $w_{*}$, taking account that $w_{*}$ varies with time or the convective velocity scale $w_{*_{0}}$ taken at the time of the maximum buoyancy flux. Figure $12 \mathrm{~b}$ shows that at surface, $\mathrm{TKE} / w_{*}$ remains relatively constant until 15:00 UTC, revealing quasi-steadiness until that time in the surface layer. After 15:00 UTC, the decrease of the normalized TKE points out that the scaling laws may not be appropriate anymore or the quasi-steadiness put into question. Later on, such a scaling becomes ill-defined at the time of zero-buoyancy flux. 

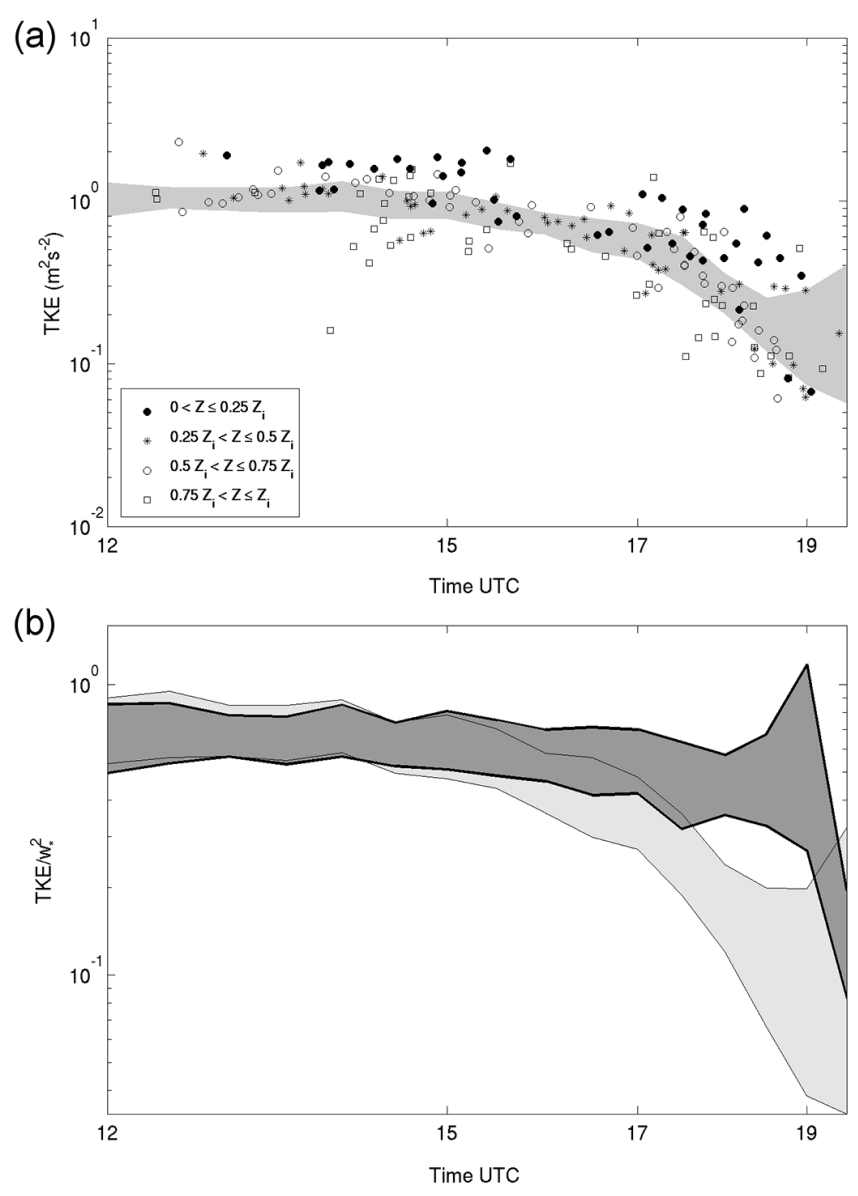

Figure 12. (a) Evolution of TKE decay observed during all IOP days (shaded area) over five different surfaces and (symbols) from the legs flown by the Piper Aztec and Sky Arrow aircraft. Note that a logarithmic scale is used on both axes. The shaded area represents the quartiles from 25 to $75 \%$ of surface estimates. The symbols for the airplane legs differ according to altitude (see inserted legend). (b) Evolution of reduced TKE over the afternoon for all IOP days over five different surfaces. Like in (a), the shaded area represents the quartiles from 25 to $75 \%$ of surface estimates. The dark grey shaded area corresponds to TKE/ $w_{*}$, and the light grey shaded area corresponds to $\mathrm{TKE} / w_{*_{0}}$, where $w_{*_{0}}$, is the convective velocity scale at the time of maximum buoyancy flux.

The TKE decay process occurs throughout the whole depth of the boundary layer during the AT as seen in Fig. 12a. This general decay is consistent with the results of Nadeau et al. (2011) who were able to model the decay observed in the surface layer with a model that included mixed-layer parameters, rather than surface-based parameterization; it also supports the normalization proposed by van Driel and Jonker (2011).

However, a further combined observations-LES analysis of the time delay of the TKE decay according to the height should give clues about the way this decay propagates with height and on the evolution of forcings throughout the AT.
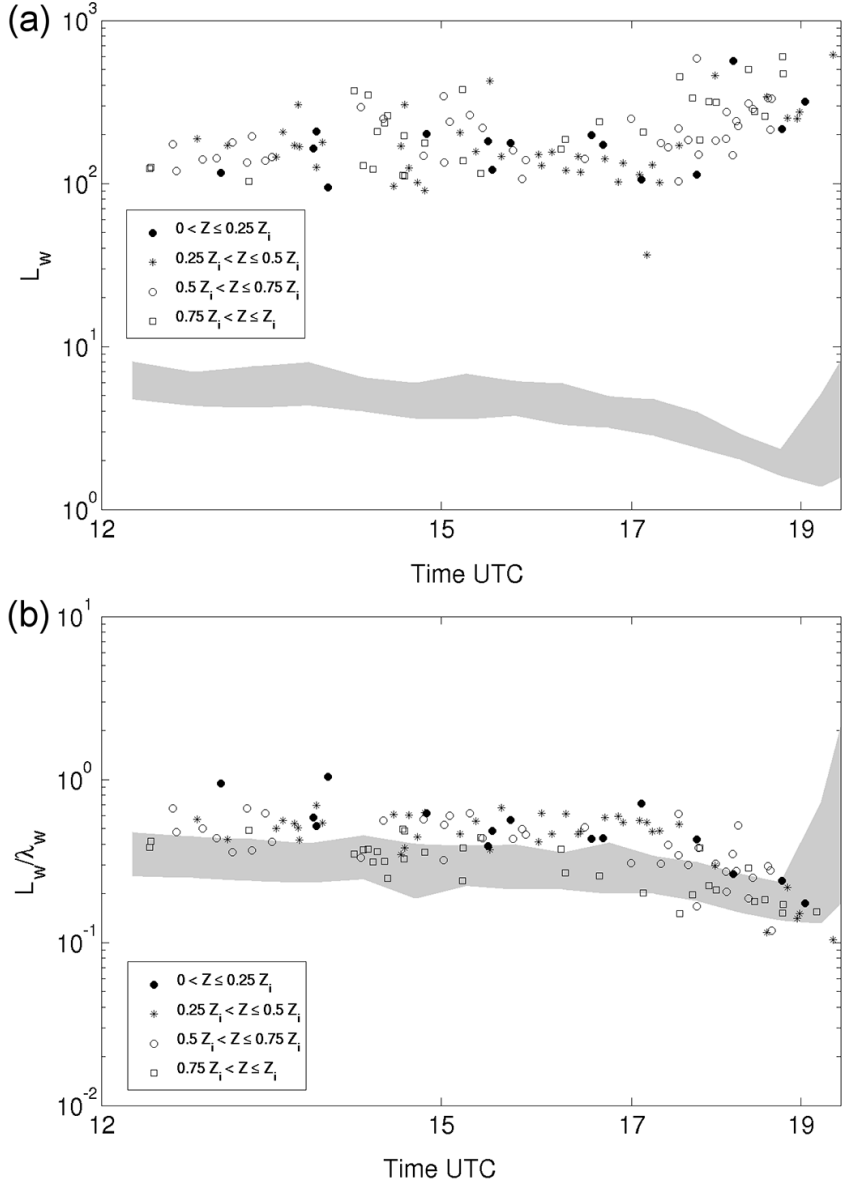

Figure 13. Time evolution of (a) the vertical wind integral scales and (b) the ratio of the integral scales to the wavelength of maximum spectral energy during all IOP days. The shaded area represents the quartiles from 25 to $75 \%$ of ground-level estimates over four different surfaces and the symbols are used for legs flown at various heights by the Piper Aztec aircraft (see inserted legend).

With the decrease of the surface fluxes and therefore the buoyancy, a decoupling might appear between the lower part of the still well-mixed CBL and the upper part, within which the TKE starts to decrease, as suggested by the remotesensing observations shown in Fig. 10. This is further addressed by Darbieu et al. (2014) on a BLLAST case study. However, this is without considering strong shear and entrainment at the CBL top which might be able to partly maintain the TKE, increasing the relative contribution of the transport term in the TKE budget, as underlined by Grant (1997). Preliminary analysis of the decay observed as a function of the synoptic conditions reveals the role that wind shear might play in delaying the abrupt decay phase (not shown), which supports the results found by Pino et al. (2006) with LES and by Goulart et al. (2010) with a theoretical model. The diversity of the conditions observed during BLLAST, together with measurements at different heights during the AT, will allow a sensitivity analysis of the TKE decay with respect to 
the various forcing influences. Further analysis of BLLAST data set should also allow us to determine for how long the CBL remains quasi-steady in its whole depth, and whether unsteadiness and departure from usual scaling occur simultaneously with the decoupling of the upper and lower part of the CBL.

\subsection{Evolution of integral scales}

The BLLAST experiment can bring new insight on the turbulence scale evolution during the AT and ET by combining in situ measurements in the surface layer (from 2 to $60 \mathrm{~m}$ ), in situ high frequency measurements under tethered balloon at around $300 \mathrm{~m}$ height, a succession of aircraft flights from noon to sunset in the whole mixed layer and Doppler lidar vertical profiles of the vertical velocity.

Figure 13a shows the evolution of the integral scale $L_{w}$ of the vertical wind during all IOPs, based on the Piper Aztec flights and on surface measurements. The integral scale, which gives a characteristic eddy size, is estimated by integrating the vertical wind autocorrelation function from zero lag to the lag at which it drops to zero (Lenschow and Stankov, 1986). Another scale is the wavelength of the maximum spectral energy, which is estimated by fitting the observed spectra with a simple analytical model of type $S(n) \propto \frac{1}{1+\frac{3}{2}\left(\frac{n}{n_{0}}\right)^{5 / 3}}$, where $S$ is the spectral energy density, $n$ is the frequency and $n_{0}$ is the frequency of maximum energy. As expected, the integral scale increases with height: it is lower than $10 \mathrm{~m}$ near the surface and larger than $100 \mathrm{~m}$ in the mixed layer. Close to the surface, the integral scale decreases after 14:30 UTC, whereas it increases in the mixed layer slightly after 17:00 UTC. That is it varies little for a long part of the AT. This result partly agrees with Nieuwstadt and Brost (1986) or Pino et al. (2006) who pointed out a quite constant turbulence length scale of vertical velocity during the AT, whereas the later sharper increase of the scale that we observe rather agrees with Grant (1997). However, it is important to note that the definitions of the turbulence length scale may differ from one study to the other, even if they should be proportional during convective conditions.

This is further illustrated in Fig. 13b, which shows the evolution of the ratio of the integral scale to the wavelength $\lambda_{\mathrm{w}}$ of the maximum spectral energy of the vertical velocity during all IOPs, based on the Piper Aztec flights and on surface measurements. This is an interesting way to normalize the integral scale, as it does not depend on $Z_{i}$, which becomes ambiguous when the turbulent mixed layer and the top inversion have decoupled. During midday, we find a ratio of about 0.35 at surface and about 0.15 within the above CBL, in agreement with Lenschow and Stankov (1986) (see the profile in their Fig. 6). Interestingly, this ratio remains constant until $16: 30$ or 17:00 UTC, that is until the more abrupt phase of the TKE decay. At this time, it decreases with time at the surface imposed by a slower change in the integral scales than in the wavelength of the maximum spectral energy, and it increases above, in relation with a faster change in the integral scales than in the wavelength of the maximum spectral energy.

This raises the question of the possible decoupling with height of the turbulence processes during the AT, which is addressed by Darbieu et al. (2014) who also study the evolution of the turbulence structure based on a spectral analysis of both LES and observations.

\section{Conclusions}

One of the main strengths of BLLAST project and field campaign is its focus on a well-defined issue: turbulence decay during the afternoon over land. Added to this, the large collaborative efforts that enabled assembling almost all the observational platforms that are useful for probing the PBL, as well as a complete hierarchy of modelling tools have resulted in a rich data set for the study of the changing characteristics of turbulence during the AT and ET, throughout 12 IOP days. The field campaign took place in an environment of complex and heterogeneous terrain, which is both a challenge and an opportunity to link the AT and ET processes with mountainplain flow reversal and surface heterogeneity.

The combination of manned and unmanned aircraft, together with numerous remote-sensing systems and in situ techniques, each one with different capabilities, enable the interested community to (i) test and validate new sensors and techniques, (ii) gain a critical insight into (old and new) techniques through redundancy and (iii) participate in the process studies of the AT and ET.

In particular, the frequent soundings of the atmosphere, with various techniques, have yielded a detailed description of the rapid evolution of the vertical structure of the lower troposphere. The numerous and complementary in situ and remote-sensing observations of turbulence give an unprecedented exploration of turbulence decay during the AT, and should enable us to make another step forward in the understanding and modelling of this process. Our preliminary analyses indicate that, in a broad sense, the decay of TKE within the surface layer behaves quite similarly to that in the CBL and residual layer above, although the decay of dissipation rate is often first observed in the upper part of the CBL. The turbulence integral scale highlights a more visible difference between the near-surface layer and above with opposite trends in time: a decrease of the turbulence scale near the surface and an increase above in late afternoon. The CBL seems to remain in quasi-steady state in the first part of the afternoon; although, during the second phase of the AT which one may call the "late afternoon transition", the turbulence structure starts to change and depart from the Deardorff scaling. Further analysis should allow us to relate the loss of quasisteadiness and validity of the usual scaling with the potential decoupling between the upper and lower part of the CBL, and with a change in TKE budget contributions. 
Closely integrated with the field experiment, numerical studies are currently underway with complementary types of models that enable us to further interpret the observations and test our hypotheses. Some of the numerical modelling and simulation activities include (1) using forecast models (tested with BLLAST data set in Couvreux et al., 2014) and mesoscale research models (Angevine et al., 2014; Jiménez et al., 2014; Jiménez and Cuxart 2014a, b; Sastre et al., 2014) to aid in understanding the large-scale circulation and forcing within which the CBL develops, and for developing and testing parameterizations of the CBL; (2) using mixed-layer models for understanding basic process interactions and conceptualization of the questions raised (Pietersen et al., 2014; Blay-Carreras et al., 2014a); (3) using LES, which are able to resolve eddies down to a few meters (Pietersen et al., 2014; Darbieu et al., 2014; Blay-Carreras et al., 2014a), for better understanding the turbulence processes that we observe. Those three aspects should also help us to better understand the potential difficulties presented by the AT for forecast or research models. BLLAST will thus contribute to the design of advanced high-resolution numerical simulations, by providing complementary data and allowing both more realistic simulations and a means to evaluate them. 


\section{Appendix A}

Table A1. Surface stations deployed during BLLAST: altitude, characteristics of the vegetation and measurements heights. The instruments used over each station are given in Table A2.

\begin{tabular}{llll}
\hline Site & Land use & $\begin{array}{l}\text { Station height } \\
\text { (m a.s.1.) }\end{array}$ & $\begin{array}{l}\text { Instrumentation levels } \\
\text { (m a.g.1.) }\end{array}$ \\
\hline \multirow{2}{*}{ ss1 } & Wheat, rhye and peas & 582 & $\begin{array}{l}0.5 \text { to } 5.8 \\
0.5 \text { to } 5.8 \\
1 \text { to } 2.89\end{array}$ \\
& Grass & 581 & 0.1 to 8.22 \\
\hline \multirow{2}{*}{ ss2 } & Grass & 581 & 0 to 9 \\
\hline \multirow{2}{*}{ ss3 } & Grass shrubs & $591 \pm 5$ & $2,15,30,45,60$ \\
\hline \multirow{2}{*}{ ss4 } & Mixed (60 m tower) & 601 & 21.8 to 31.5 \\
\hline \multirow{2}{*}{ ss5 } & Douglas Fir (20-25 m height) & 620 & 6 \\
\hline \multirow{2}{*}{ ss6 } & Corn (0.4-1.5 m height) & $645 \pm 5$ & 2 \\
\hline \multirow{2}{*}{ ss7 } & Moor & $641 \pm 3$ & \\
\hline
\end{tabular}


Table A2. List of the variables measured at the surface sites (first column), instruments used (second column) and their acquisition frequency (third column). The abbreviation for the measured variables are $T$ : temperature, WS: wind speed, WD: wind direction, $\mathrm{H}_{2} \mathrm{O}$ : humidity, $\mathrm{CO}_{2}$ : carbon dioxide concentration, P: pressure, Rad: radiative budget terms, ST: soil temperature, SM: soil moisture, G: ground heat flux. For each surface station, the number of specific instruments installed is indicated (columns 4 to 12). Note that the lines in italic correspond to high frequency instruments.

\begin{tabular}{|c|c|c|c|c|c|c|c|c|c|c|c|}
\hline & \multirow[t]{2}{*}{ Instrument } & \multirow[t]{2}{*}{ Acq. Freq. $(\mathrm{Hz})$} & \multicolumn{3}{|c|}{ ss 1} & \multirow[t]{2}{*}{ ss2 } & \multirow[t]{2}{*}{ ss 3} & \multirow[t]{2}{*}{ ss 4} & \multirow[t]{2}{*}{ ss 5} & \multirow{2}{*}{$\begin{array}{c}\text { ss6 } \\
\text { corn }\end{array}$} & \multirow{2}{*}{$\begin{array}{c}\text { ss7 } \\
\text { moor }\end{array}$} \\
\hline & & & wheat & grass & edge & & & & & & \\
\hline$T, \mathrm{H}_{2} \mathrm{O}$ & Campbell HMP45 & 0.1 & \multirow{5}{*}{5} & \multirow{5}{*}{5} & & \multirow[b]{5}{*}{9} & \multirow{5}{*}{1} & \multirow[t]{5}{*}{5} & \multirow[t]{5}{*}{1} & 1 & 1 \\
\hline & Campbell Thermocouple ASP TC & 0.016 & & & & & & & & \multirow{4}{*}{1} & \multirow{4}{*}{1} \\
\hline$T, \mathrm{H}_{2} \mathrm{O}$ & Psychrometer & 0.1 & & & & & & & & & \\
\hline $\mathrm{H}_{2} \mathrm{O}$ & Atexis PT1000 classe A & 0.016 & & & & & & & & & \\
\hline$T$ & Campbell Thermocouple E-TYPE FW05 & 20 & & & & & & & & & \\
\hline WS & Vector Instrument A100LK & 0.016 & \multirow{9}{*}{$\begin{array}{l}5 \\
1\end{array}$} & \multirow{5}{*}{$\begin{array}{l}5 \\
1\end{array}$} & \multirow{9}{*}{1} & \multirow{9}{*}{$\begin{array}{l}4 \\
2\end{array}$} & 3 & & \multirow{9}{*}{2} & \multirow{9}{*}{1} & \multirow{9}{*}{1} \\
\hline WD & VectorInstrument W200P & 0.016 & & & & & 3 & & & & \\
\hline WS & Cup anemometer & 0.1 & & & & & & 1 & & & \\
\hline WD & Vane & 0.1 & & & & & & 1 & & & \\
\hline WS, WD & Young 05103 & 0.016 & & & & & & 1 & & & \\
\hline$T, W S, W D$ & Campbell-scientific-CSAT-sonic-anemo & $10-20$ & & 1 & & & 1 & 2 & & & \\
\hline$W S, W D$ & Kaio Denki & $10-20$ & & & & & & & & & \\
\hline$T, W S, W D$ & Gill master pro sonic anemometer & 10 & & & & & \multirow[b]{2}{*}{1} & 1 & & & \\
\hline$W D$ & USA-1 sonic & 20 & & & & & & & & & \\
\hline $\mathrm{H}_{2} \mathrm{O}, \mathrm{CO}_{2}$ & Licor $7500 \mathrm{~A}$ CO2/H2O analyzer & 10 & 1 & 1 & 1 & & & 1 & 1 & 1 & 1 \\
\hline $\mathrm{H}_{2} \mathrm{O}$ & Campbell KH2O hygrometer & 10 & & & & & & 1 & & & \\
\hline $\mathrm{P}$ & Vaisala PTB210 & 1 & \multirow{3}{*}{1} & \multirow{3}{*}{1} & \multirow{3}{*}{1} & & & \multirow[t]{3}{*}{1} & & 1 & 1 \\
\hline $\mathrm{P}$ & Vaisala PTB100a & 1 & & & & & & & & & \\
\hline $\mathrm{P}$ & Paroscientific microbarometers & 2 & & & & & 3 & & & & \\
\hline $\operatorname{Rad}$ & CNR1 Kipp \& Zonen & 1 & 1 & 1 & & & 1 & 1 & 1 & 1 & 1 \\
\hline $\operatorname{Rad}$ & Hukseflux IR02 radiometers & 0.1 & & & & 6 & & & & & \\
\hline Rain & Rain gauge ARG100 & 0.1 & & & & & & 1 & & & \\
\hline Rain & SPIEA raingauge & 0.016 & & & & & & 1 & & 1 & 1 \\
\hline ST & Custom-built Pt100 & 0.1 & 5 & 5 & & & & & & 1 & 1 \\
\hline ST & Atexis PT 1000 Classe A & 0.016 & & & & & & & & 1 & 1 \\
\hline SM & Delta Devices THETA PROBE ML2X & 0.001 & 1 & 1 & 1 & & 30 & & & 1 & 1 \\
\hline G & Hukseflux HFP01 & 0.1 & 1 & 1 & & & 2 & 3 & & 3 & 3 \\
\hline
\end{tabular}


Table A3. Instrumentation of the Piper Aztec aircraft.

\begin{tabular}{|c|c|c|c|}
\hline Parameters & Instruments & Accuracy & $\begin{array}{l}\text { Acquisition/computation } \\
\text { frequency }\end{array}$ \\
\hline Position (lat., long. and alt.) & GPS + Inertial Navigation System & $5 \mathrm{~m}$ & $1 \mathrm{~Hz}$ \\
\hline 3-D ground speed & (IXSEA AIRINS) & $0.03 \mathrm{~m} \mathrm{~s}^{-1}$ & $100 \mathrm{~Hz}$ \\
\hline Height above the ground & Radar altimeter till $2500 \mathrm{ft}$ & $50 \mathrm{~m}$ & $1 \mathrm{~Hz}$ \\
\hline $\begin{array}{l}\text { Attitude angles (roll, pitch \& } \\
\text { true heading) }\end{array}$ & IXSEA AIRINS & $\begin{array}{l}0.005^{\circ}, 0.02^{\circ} \\
\text { for heading }\end{array}$ & $100 \mathrm{~Hz}$ \\
\hline $\begin{array}{l}\text { Horizontal wind } \\
\text { 3-D turbulent wind }\end{array}$ & Gust probe + IXSEA AIRINS & $\begin{array}{l}2 \mathrm{~m} \mathrm{~s}^{-1} \\
0.01 \mathrm{~m} \mathrm{~s}^{-1}\end{array}$ & $25 \mathrm{~Hz}$ \\
\hline Static pressure & Rosemount 1221 & $0.2 \mathrm{hPa}$ & $200 \mathrm{~Hz}$ \\
\hline Temperature & Rosemount 102E2 thermometer & $0.5^{\circ} \mathrm{C}$ & $200 \mathrm{~Hz}$ \\
\hline Relative humidity & capacitive sensor (CORECI Humicor 5000) & $\leq 5 \%$ & $50 \mathrm{~Hz}$ \\
\hline Dew point temperature & Buck Research 1011B & $\pm 0.5^{\circ} \mathrm{C}$ & $25 \mathrm{~Hz}$ \\
\hline $\mathrm{H}_{2} \mathrm{O}$ concentration (fluctuation) & Licor 7500 open-path gaz analyser & $0.003 \mathrm{~g} \mathrm{~kg}^{-1}$ & $10 \mathrm{~Hz}$ \\
\hline $\mathrm{CO}_{2}$ concentration (fluctuation) & & $0.1 \mathrm{ppb}$ & $10 \mathrm{~Hz}$ \\
\hline
\end{tabular}

Table A4. Instrumentation of the Sky Arrow aircraft.

\begin{tabular}{|c|c|c|c|}
\hline Parameters & Instruments & Accuracy & $\begin{array}{l}\text { Acquisition } \\
\text { frequency }\end{array}$ \\
\hline Position (lat, long and alt) & GPS (Novatel RT 20, single freq.) extended to & $10 \mathrm{~cm}$ accuracy & $10 \mathrm{~Hz}$ \\
\hline 3-D ground speed & $50 \mathrm{~Hz}$ with probe accelerometers & $\pm 1 \mathrm{~cm} \mathrm{~s}^{-1}$ accuracy & $10 \mathrm{~Hz}$ \\
\hline $\begin{array}{l}\text { Attitude angles (pitch, } \\
\text { roll \& true heading) }\end{array}$ & $\begin{array}{l}\text { Systron Donner C-MIGITS III GPS-INS ex- } \\
\text { tended to } 50 \mathrm{~Hz} \text { with differential accelerometers }\end{array}$ & $\begin{array}{l} \pm 0.05^{\circ} \text { (Pitch, Roll) } \pm 0.08^{\circ} \\
\text { (Heading) }\end{array}$ & $50 \mathrm{~Hz}$ \\
\hline $\begin{array}{l}3-\mathrm{D} \text { wind (mean and } \\
\text { turbulence) }\end{array}$ & Best aircraft turbulence (BAT) probe & $\begin{array}{l}\text { Turbulence acc. } \pm 2 \mathrm{~cm} \mathrm{~s}^{-1} \\
\text { mean wind acc. } \pm 0.5 \mathrm{~m} \mathrm{~s}^{-1}\end{array}$ & $50 \mathrm{~Hz}$ \\
\hline $\begin{array}{l}\text { Humidity (abs. Humidity } \\
\text { and dew point) }\end{array}$ & EdgeTech Model 200 Chilled Mirror & $\pm 0.5^{\circ} \mathrm{C}$ & $50 \mathrm{~Hz}$ \\
\hline Temperature & $\begin{array}{l}\text { Reference thermistor (mod YSI 4400) coupled } \\
\text { to fast response thermocouple }\end{array}$ & $\pm 0.2^{\circ} \mathrm{C}$ & $50 \mathrm{~Hz}$ \\
\hline Surface temperature & Everest $4000.4 \mathrm{GL}$ infrared radiometer & $\begin{array}{l}15^{\circ} \text { viewing angle, } 8-14 \mu \mathrm{m} \\
\pm 0.5^{\circ} \mathrm{C} \text { accuracy }\end{array}$ & $50 \mathrm{~Hz}$ \\
\hline Radiation & $\begin{array}{l}\text { PAR up and down-welling (mod. Licor LI190) } \\
\text { REBS Q*7 net radiometer }\end{array}$ & $\pm 5 \%$ & $50 \mathrm{~Hz}$ \\
\hline $\mathrm{CO}_{2}$ concentration & Licor 7500 open-path gas analyzer & $1 \%$ & $50 \mathrm{~Hz}$ \\
\hline $\mathrm{H}_{2} \mathrm{O}$ concentration & Licor 7500 open-path gas analyzer & $2 \%$ & $50 \mathrm{~Hz}$ \\
\hline
\end{tabular}


Table A5. RPAS which participated in the BLLAST field experiment. RPAS Weight, cruise velocity and measured variables are indicated. $T, q$, LST, Imagery, rad. and elec. stand for air temperature $\left({ }^{\circ} \mathrm{C}\right)$, specific humidity $\left(\mathrm{g} \mathrm{kg}^{-1}\right)$, land surface temperature $\left({ }^{\circ} \mathrm{C}\right)$, downward short-wave radiation $\left(\mathrm{W} \mathrm{m}^{-2}\right.$ ), and electric charges, respectively. Note that the RPAS Syrius Busca, Funjet1 and Funjet2 do not appear in Table 2, as they did not fly during IOP days.

\begin{tabular}{|c|c|c|c|c|c|c|c|c|}
\hline \multirow[t]{2}{*}{ Airframe } & \multirow[t]{2}{*}{ Reference } & \multirow{2}{*}{$\begin{array}{l}\text { Weight } \\
\text { Cruise velocity }\end{array}$} & \multicolumn{6}{|c|}{ Acquisition frequency $(\mathrm{Hz})$ of the measured variables } \\
\hline & & & $T$ and $q$ & 3-D wind & LST & imagery & rad. & elec. \\
\hline SUMO & $\begin{array}{l}\text { Reuder et al. (2012b) } \\
\text { Nicoll and Harrison (2012) }\end{array}$ & $\begin{array}{l}0.6 \mathrm{~kg} \\
54 \mathrm{kmh}^{-1}\end{array}$ & 2 & 100 & 2 & & 10 & 10 \\
\hline MASC & $\begin{array}{l}\text { Van den Kroonenberg } \\
\text { et al. (2012) }\end{array}$ & $\begin{array}{l}5 \mathrm{~kg} \\
90 \mathrm{~km} \mathrm{~h}^{-1}\end{array}$ & 100 & 100 & & & & \\
\hline $\mathrm{M} 2 \mathrm{AV}$ & Martin et al. (2011) & $\begin{array}{l}6 \mathrm{~kg} \\
80 \mathrm{~km} \mathrm{~h}^{-1}\end{array}$ & 100 & 100 & & & & \\
\hline Octo-copter & & $\begin{array}{l}1.7 \mathrm{~kg} \\
18 \mathrm{~km} \mathrm{~h}^{-1}\end{array}$ & 50 & & 50 & & & \\
\hline Sirius I & & $\begin{array}{l}2.7 \mathrm{~kg} \\
65 \mathrm{~km} \mathrm{~h}^{-1}\end{array}$ & 8 & & 8 & About $0.5-1^{*}$ & & \\
\hline BUSCA & & $\begin{array}{l}1.6 \mathrm{~kg} \\
60 \mathrm{~km} \mathrm{~h}^{-1}\end{array}$ & 2 & & & & & \\
\hline $\begin{array}{l}\text { Funjet1 } \\
\text { Funjet } 2\end{array}$ & & $\begin{array}{l}0.7 \mathrm{~kg} \\
54 \mathrm{~km} \mathrm{~h}^{-1}\end{array}$ & 2 & & & & & \\
\hline
\end{tabular}

* Triggered by autopilot to ensure $85 \%$ image overlap. 
Acknowledgements. The BLLAST field experiment was made possible thanks to the contribution of several institutions and supports: INSU-CNRS (Institut National des Sciences de l'Univers, Centre national de la Recherche Scientifique, LEFE-IMAGO program), Météo-France, Observatoire Midi-Pyrénées (University of Toulouse), EUFAR (EUropean Facility for Airborne Research) BLLATE-1\&2, COST ES0802 (European Cooperation in the field of Scientific and Technical) and the Spanish MINECO projects CGL2009-08609, CGL2012-37416-C04-03, CGL2012-37416C04-02 and CGL2011-13477-E. The field experiment would not have occurred without the contribution of all participating European and American research groups, which all have contributed in a significant amount. The Piper Aztec research airplane is operated by SAFIRE, which is a unit supported by INSU-CNRS, Météo-France and the French Spatial Agency (CNES). BLLAST field experiment was hosted by the instrumented site of Centre de Recherches Atmosphériques, Lannemezan, France (Observatoire Midi-Pyrénées, Laboratoire d'Aérologie). Its $60 \mathrm{~m}$ tower is partly supported by the POCTEFA/FLUXPYR European program. BLLAST data are managed by SEDOO, from Observatoire Midi-Pyrénées. See http://bllast.sedoo.fr for all contributions. Since 2013, the French ANR supports BLLAST analysis. Finally, we thank Harm J. J. Jonker, Robert J. Beare and Zbignew Sorbjan for fruitful discussions.

Edited by: R. J. Beare

\section{References}

Acevedo, O. and Fitzjarrald, D. R.: The early evening surface-layer transition: Temporal and spatial variability, J. Atmos. Sci., 58, 2650-2667, 2001.

André J.-C., De Moor, G., Lacarrère, P., Therry, G., and du Vachat, R.: Modeling the 24-hour evolution of the mean and turbulent structures of the planetary boundary layer, J. Atmos. Sci., 78, 1861-1883, 1978.

Angevine, W. M.: Transitional, entraining, cloudy, and coastal boundary layers, Acta Geophys., 56, 2-20, 2008.

Angevine, W. M., White, A. B., and Avery, S. K.: Boundary-layer depth and entrainment zone characterization with a boundarylayer profiler, Bound.-Lay. Meteorol., 68, 375-385, 1994.

Angevine, W. M., Grimsdell, A. W., Hartten, L. M., and Delany, A. C.: The Flatland Boundary Layer Experiments, B. Am. Meteorol. Soc., 79, 419-431, 1998.

Angevine, W. M., Bazile, E., Legain, D., and Pino, D.: Land surface spinup for episodic modeling, Atmos. Chem. Phys., 14, 81658172, doi:10.5194/acp-14-8165-2014, 2014.

Aupetit, H.: Les Visiteurs du ciel: Guide de l'air pour l'homme volant, Edition Rétine, Paris, France, 394 pp., 1989.

Baas, P., Bosveld, F. C., Baltink, H. K., and Holtslag, A. A. M.: A climatology of nocturnal low-level jets at Cabauw, J. Appl. Meteorol. Climatol., 48, 1627-1642, 2009.

Batchelor, G. K.: An Introduction to Fluid Mechanics, Cambridge University Press, London, 1967.

Banta, M., Senif, J., and Fehsenfeld, F. C.: Daytime buildup and nighttime transport of urban ozone in the boundary layer during a stagnation episode, J. Geophys. Res., 103, 22519-22544,, 1998.

Banta, R. M., Pichugina, Y. L., and Newsom, R. K.: Relationship between Low-Level Jet Properties and Turbulence Kinetic En- ergy in the Nocturnal Stable Boundary Layer, J. Atmos. Sci., 60, 2549-2555, 2003.

Basu, S., Vinuesa, J.-F., and Swift, A.: Dynamic LES Modeling of a Diurnal Cycle, J. App. Meteorol. Climatol., 47, 1156-1174, 2008.

Beare, R. J., Edwards, J. M., and Lapworth, A. J.: Simulation of the observed evening transition and nocturnal boundary layers: large-eddy modelling, Q. J. R. Meteorolog. Soc., 132, 81-99, 2006.

Berkowitz C. M., Fast J. D., Springston S. R., Larsen R. J., Spicer C. W., Doskey P. VHubbe., J. M., and Plastridge R.: Formation mechanisms and chemical characteristics of elevated photochemical layers over the northeast United States, J. Geophys. Res., 103, 10631-10647, 1998.

Beyrich, F. and Mengelkamp, H.-T.: Evaporation over a Heterogeneous Land Surface: EVA_GRIPS and the LITFASS-2003 Experiment - An Overview, Bound.-Lay. Meteorol., 121, 5-32, 2006.

Beyrich, F. and Engelbart, D. A. M.: Ten years of operational boundary-layer measurements at the Richard-Assmann Observatory Lindenberg: The role of remote sensing. 14th International Symposium for the Advancement of Boundary Layer Remote Sensing, 23-25 June 2008, Tech. Univ. of Denmark, Copenhagen, Denmark, 2008.

Blay-Carreras, E., Pino, D., Vilà-Guerau de Arellano, J., van de Boer, A., De Coster, O., Darbieu, C., Hartogensis, O., Lohou, F., Lothon, M., and Pietersen, H.: Role of the residual layer and large-scale subsidence on the development and evolution of the convective boundary layer, Atmos. Chem. Phys., 14, 4515-4530, doi:10.5194/acp-14-4515-2014, 2014a.

Blay-Carreras, E., Pardyjak, E. R., Pino, D., Alexander, D. C., Lohou, F., and Lothon, M.: Countergradient heat flux observations during the evening transition period, Atmos. Chem. Phys., 14, 9077-9085, doi:10.5194/acp-14-9077-2014, 2014b.

Bonin, T., Chilson, P., Zielke, B., and Fedorovitch, E.: Observations of the Early Evening Boundary-Layer Transition Using a Small Unmanned Aerial System, Bound.-Lay. Meteorol., 146, 119-132, 2013.

Bosveld, F. C., Baas, P., van Meijgaard, E., de Bruijn, E. I.-F., Steeneveld, G.-J., and Holtslag, A. A. M.: The third GABLS intercomparison case for evaluation studies of boundary-layer models. Part A: Case Selection and Set-up, Bound.-Lay. Meteorol., 152, 133-156, 2014.

Brazel, A. J., Fernando, H. J. S., Hunt, J. C. R., Selover, N., Hedquist, B. C., and Pardyjak, E. R.: Evening Transition Observations in Phoenix, Arizona, J. Appl. Meteorol., 44, 99-112, 2005.

Brooks, I. M. and Fowler, A. M.: An Evaluation of BoundaryLayer Depth, Inversion and Entrainment Parameters by LargeEddy Simulation, Bound.-Lay. Meteorol., 142, 245-263, 2011.

Canut, G., Couvreux, F., Lothon, M., Pino, D., and Saïd, F.: Observations and Large-Eddy Simulations of Entrainment in the Sheared Sahelian Boundary Layer, Bound.-Lay. Meteorol., 142, 79-101, 2012.

Canut, G., Legain, D., Piguet, B., Moulin, E., and Tzanos, D.: The eddy-covariance method applied in a tethered-balloon, Atmos. Meas. Tech. Discuss., in preparation, 2014.

Casso-Torralba, P. J., Vilà-Guerau de Arellano, J., Bosveld., F., Soler, M. R., Vermeulen, A., Werner, C., and Moors, E.: Diurnal 
and vertical variability of the sensible heat and carbon dioxide budgets in the atmospheric surface layer, J. Geophys. Res., 113, D12119, doi:10.1029/2007JD009583, 2008.

Cohn, S. A., Mayor, S. D., Grund, C. J., Weckwerth, T. M., and Senff, C.: The Lidars in Flat Terrain (LIFT) Experiment, B. Am. Meteorol. Soc., 79, 1329-1343, 1998.

Cole, G. and Fernando, H.: Some aspects of the decay of convective turbulence, Fluid Dyn. Res., 23, 161-176, 1998.

Courtier, P. and Geleyn, J.-F.: A global numerical weather prediction model with variable resolution - Application to the shallowwater equations, Q. J. R. Meteorolog. Soc., 114, 1321-1346, 1988.

Couvreux, F., Bazile, E., Seity, Y., Lothon, M., Guichard, F., Canut, G., Lohou, F., Pietersen, H., and Legain, D.: Representation of the afternoon transition in Numerical Weather Prediction models: evaluation with BLLAST dataset, in preparation for Atmos. Chem. Phys. Discuss., 2014.

Cuijpers J. W. M. and Holtslag A. A. M.: Impact of skewness and nonlocal effects on scalar and buoyancy fluxes in convective boundary layers, J. Atmos. Sci., 55, 151-162, 1998.

Cuxart, J., Yagüe, C., Morales, G., Terradellas, E., Orbe, J., Calvo, J., Fernández, A., Soler, M. R., Infante, C., Buenestado, P., Espinalt, A., Joergensen, H. E., Rees, J. M., Vilà-Guerau de Arellano, J., Redondo, J. M., Cantalapiedra, I. R., and Conangla, L.: Stable Atmospheric Boundary-Layer Experiment in Spain (SABLES 98): A Report, Bound.-Lay. Meteorol., 96, 337-370, 2000.

Cuxart, J., and Jiménez, M. A.: Mixing processes in a nocturnal low-level jet: An LES study, J. Atmos. Sci., 64, 1666-1679, 2007.

Cuxart, J.: Nocturnal basin low-level jets: an integrated study, Acta Geophys., 56, 100-113, 2008.

Cuxart, J., Wrenger, B., Duennermann, J., Martinez, D., Jiménez, M. A., Conangla, L., Reuder, J., Jonassen, M. O., Lothon, M., Saïd, F., and Lohou, F.: Sub-kilometric heterogeneity effects on the surface energy budget in BLLAST'11, Atmos. Chem. Phys. Discuss., in preparation, 2014.

Darbieu, C., Lohou, F., Lothon, Vilà-Guerau de Arellano, J., Durand, P., Blay, E., and Pino, D.: Turbulence vertical structure of the boundary layer during the late afternoon transition, Atmos. Chem. Phys. Discuss., in preparation, 2014.

Deardorff, J. W.: Convective velocity and temperature scales for the unstable planetary boundary layer and for Rayleigh convection, J. Atmos. Sci., 27, 1211-1215, 1970.

Deardorff, J. W.: Numerical investigation of neutral and unstable planetary boundary layers, J. Atmos. Sci., 29, 91-115, 1972.

Derbyshire, S. H.: Nieuwstadt's stable boundary layer revisited, Q. J. R. Meteorol. Soc., 116, 127-158, 1990.

Edwards, J. M., Beare, R. J., and Lapworth, A. J.: Simulation of the observed evening transition and nocturnal boundary layers: single column modelling, Q. J. R. Meteorol. Soc., 132, 61-80, 2006.

Fernando, H. J. S.: Turbulent mixing in stratified fluids, Annu. Rev. Fluid Mech., 23, 455-493, 1991.

Fernando, H. J. S., Princevac, M., Pardyjak, E., and Data, A.: The decay of convective turbulence during evening transition period, Proc. of the 11th Conference on Mountain Meteorology and MAP Meeting, Bartlett (NH), USA, paper 10.3, 2004.
Fernando, H. J. S., Verhoef, B., Di Sabatino, S., Leo, L. S., and Park, S.: The Phoenix Evening Transition Flow Experiment (TRANSFLEX), Bound.-Lay. Meteorol., 147, 443-468, 2013.

Fernando, H. J. S. and Pardyjak, E. R.: Field studies delve into the intricacies of mountain weather, Eos T. Am. Geophys. Un., 94, 313-315, 2013.

Fitzjarrald, D. R., Freedman, J. M., Czikowsky, M. J., Sakai, R. K., Acevedo, O. C., and Moraes, O. L. L.: Momentum and scalar transport during the decay of CBL turbulence, In: Proc: 16th AMS Symposium on boundary layers and turbulence, 9-13 August 2004, Portland (ME), USA, paper 4.23, 2004.

Freedman, J. M., and Fitzjarrald, D. R.: Postfrontal Airmass Modification, J. Hydrol., 2, 419-437, doi:10.1175/15257541(2001)002<0419:PAM>2.0.CO;2, 2001.

Garai, A., Pardyjak, E., Steeneveld, G.-J., and Kleissl, J.: Surface Temperature and Surface-Layer Turbulence in a Convective Boundary Layer, Bound.-Lay. Meteorol., 148, 51-72, 2013.

Garratt, J. R.: The atmospheric boundary layer, Cambridge University Press, 316 pp., 1992.

Gioli, B., Miglietta, F., Vaccari, F. P., Zaldei, A., and De Martino, B.: The Sky Arrow ERA, an innovative airborne platform to monitor mass, momentum and energy exchange of ecosystems, Ann. Geophys., 49, 109-116, 2006, http://www.ann-geophys.net/49/109/2006/.

Goulart, A. G., Bodmann, B. E. J., Vilhena, M. T. M. B., Soares, P. M. M., and Moreira, D. M.: On the Time Evolution of the Turbulent Kinetic Energy Spectrum for Decaying Turbulence in the Convective Boundary Layer, Bound.-Lay. Meteorol., 138, 61-75, 2010.

Grant, A. L. M.: An observational study of the evening transition boundary-layer, Q. J. R. Meteorolog. Soc., 123, 657-677, 1997.

Grimsdell, A. W. and Angevine, W. M.: Observations of the afternoon transition of the convective boundary layer, J. Appl. Meteorol., 41, 3-11, 2002.

Hartogensis, O. K., De Bruin, H. A. R., and van de Wiel, B. J. H.: Displaced-beam small aperture scintillometer test. part ii: CASES-99 stable boundary-layer experiment, Bound.-Lay. Meteorol., 105, 149-176, 2002.

Heo, B.-H., Jacoby-Koaly, S., Kim, K. E., Campistron, B., Benech, B., and Jung, E.-S.: Use of the Doppler Spectral Width to Improve the Estimation of the Convective Boundary Layer Height from UHF Wind Profiler Observations, J. Atmos. Ocean. Technol., 20, 408-424, 2003.

Hess, G., Hicks, B., and Tetsuji, Y.: The impact of the Wangara experiment, Bound.-Lay. Meteorol., 20, 135-174, 1981.

Holtslag, A. A. M., Svensson, G., Baas, P., Basu, S., Beare, R., Beljaars, A. C. M., Bosveld, F. C., Cuxart, J., Lindvall, L., Steeneveld, G. J., Tjernström, M., and Van De Wiel, B. J. H.: Stable Atmospheric Boundary Layers and Diurnal Cycles: Challenges for Weather and Climate Models, B. Am. Meteorol. Soc., 94, 1691-1706, 2013.

Horst, T. W., Kleissl, J. Lenschow, D. H., Meneveau, C., Moeng, C.H., Parlange, M. B., Sullivan, P. P., and Weil, J. C.: HATS: Field Observations to Obtain Spatially Filtered Turbulence Fields from Crosswind Arrays of Sonic Anemometers in the Atmospheric Surface Layer. J. Atmos. Sci., 61, 1566-1581, 2004.

Hurley, P. and Luhar, A.: Modelling the meteorology at the Cabauw tower for 2005, Bound.-Lay. Meteorol., 132, 43-57, 2009. 
Jacobson, M. Z.: Fundamentals of Atmospheric Modeling, Cambridge University Press, 666 pp., 2000.

Jacoby-Koaly, S., Campistron, B., Bernard, S., Benech, B., GirardArdhuin, F., Dessens, J., Dupont, E., and Carissimo, B.: Turbulent dissipation rate in the boundary layer via UHF wind profiler Doppler spectral width measurements, Bound.-Lay. Meteorol., 103, 361-389, 2002.

Jiménez, M. A., Angevine, W. M., Bazile, E., Couvreux, F., Cuxart, J., Pino, D., and Sastre, M.: An intercomparison of mesoscale simulations during the Boundary Layer Late Afternoon and Sunset Turbulence (BLLAST) experimental field campaign, Proceedings of the 21st Symposium on Boundary-Layers and Turbulence, 9-13 June, Leeds, 2014.

Jiménez, M. A. and Cuxart, J.: A study of the nocturnal flows generated in the north side of the Pyrénées, Atmos. Res., 145-146, 244-254, doi:10.1016/j.atmosres.2014.04.010, 2014a.

Jiménez, M. A. and Cuxart, J.: Downslope and down-valley winds during the BLLAST'11 campaign, Atmos. Chem. Phys. Discuss., in preparation, $2014 \mathrm{~b}$.

Kaimal, J. C., Wyngaard, J. C., Haugen, D. A., Coté, O. R., Izumi, Y., Caughey, S. J., and Readings, C. J.: Turbulence Structure in the Convective Boundary Layer, J. Atmos. Sci., 33, 2152-2169, 1976.

Kaimal, J. and Wyngaard, J.: The Kansas and Minnesota experiments, Bound.-Lay. Meteorol., 50, 31-47, 1990.

Kaimal J. C. and Finnigan, J. J.: Atmospheric boundary layer flows - their structure and measurement, Oxford University press, 289 pp., 1994.

Kumar, V., Kleissl, J., Meneveau, C., and Parlange, M. B.: Largeeddy simulation of a diurnal cycle of the atmospheric boundary layer: Atmospheric stability and scaling issues, Water Resour. Res., 42, 3-18, 2006.

Legain, D., Bousquet, O., Douffet, T., Tzanos, D., Moulin, E., Barrie, J., and Renard, J.-B.: High-frequency boundary layer profiling with reusable radiosondes, Atmos. Meas. Tech., 6, 21952205, doi:10.5194/amt-6-2195-2013, 2013.

Lenschow, D. H.: Model of the height variation of the turbulence kinetic energy budget in the unstable planetary boundary layer, J. Atmos. Sci., 31, 465-474, 1974.

Lenschow, D. H. and Stankov, B. B.: Length scales in the convective boundary layer, J. Atmos. Sci., 43, 1198-1209, 1986.

Lilly, D. K.: The representation of small-scale turbulence in numerical simulation experiments, Proc. of IBM scientific computing symposium on environmental sciences, Yorktown heights, USA, 1967.

Lohou, F., Saïd, F., Lothon, M., Durand, P., and Serça, D.: Impact of Boundary-Layer Processes on Near-Surface Turbulence Within the West African Monsoon, Bound.-Lay. Meteorol., 136, 1-23, 2010.

Lothon, M., Lenschow, D. H., and Mayor, S. D.: Coherence and scale of vertical velocity in the convective boundary layer from a Doppler lidar, Bound.-Lay. Meteorol., 121, 521-536, 2006.

Lothon, M., Lenschow, D. H., and Mayor, S.: Coherence and scale of vertical velocity in the convective boundary-layer, Bound.Lay. Meteorol., 121, 521-536, 2006.

Lundquist, J. K.: Intermittent and Elliptical Inertial Oscillations in the Atmospheric Boundary Layer, J. Atmos. Sci., 60, 2661-2673, 2003.
Mahrt, L. and Lenschow D. H.: Growth dynamics of the convectively mixed layer, J. Atmos. Sci., 33, 41-51, 1976.

Mahrt, L.: The early evening boundary layer transition, Q. J. R. Meteorol. Soc., 107, 329-343, 1981.

Mahrt, L.: Stratified atmospheric boundary layers, Bound.-Lay. Meteorol., 90, 375-396, 1999.

Mahrt, L., Vickers, D., Nakamura, R., Soler, M. R., Sun, J., Burns, S., and Lenschow, D. H.: Shallow drainage flows, Bound.-Lay. Meteorol., 101, 243-260, 2001.

Mahrt, L.: Stably stratified boundary layers, Annu. Rev. Fluid Mech., 46, 23-45, 2014.

Manins, P. C. and Sawford, B. L.: Katabatic winds: A field case study, Q. J. R. Meteorol. Soc., 105, 1011-1025, 1979.

Martin, S., Bange, J., and Beyrich, F.: Meteorological profiling of the lower troposphere using the research UAV "M2AV Carolo", Atmos. Meas. Tech., 4, 705-716, doi:10.5194/amt-4-705-2011, 2011.

McNaughton, K. G., Clement, R. J., and Moncrieff, J. B.: Scaling properties of velocity and temperature spectra above the surface friction layer in a convective atmospheric boundary layer, Nonlinear Processes Geophys., 14, 257-271, 2007.

Moene, A. F., Beyrich, F. B., and Hartogensis, O. K.: Developments in scintillometry, B. Am. Meteorol. Soc., 90, 694-698, 2009.

Moeng, C.-H.: A large-eddy-simulation model for the study of planetary boundary-layer turbulence, J. Atmos. Sci., 41, 2052-2062, 1984.

Moeng, C.-H. and Sullivan, P. P.: A comparison of shear and buoyancy driven planetary-boundary-layer flows. J. Atmos. Sci., 51, 999-1022, 1994.

Monin, A. S. and Obukhov, A. M.: Basic laws of turbulent mixing in the surface layer of the atmosphere, Tr. Akad. Nauk SSSR Geofiz., 24, 163-187, 1954.

Monin, A. S. and Yaglom, A. M.: Statistical fluid mechanics, Vol. 2. edited by: Lumley, J. L., The MIT Press, Massachusetts, 1975.

Nadeau, D. F., Pardyjak, E. R., Higgins, C. W., Fernando, H. J. S., and Parlange, M. B.: A simple model for the afternoon and early evening decay of convective turbulence over different land surfaces, Bound.-Lay. Meteorol., 141, 301-324, 2011.

Nicoll, K. A. and Harrison, R. G.: Balloon-borne disposable radiometer for cloud detection, Rev. Sci. Instrum., 83, 025111, doi:10.1063/1.3685252, 2012.

Nieuwstadt, F. T. M.: The turbulent structure of the stable, nocturnal boundary layer, J. Atmos. Sci. 41, 2202-2216, 1984.

Nieuwstadt, F. T. M. and Brost, R. A.: The decay of convective turbulence, J. Atmos. Sci., 43, 532-546, 1986.

Pardyjak, E. R.: Atmospheric boundary layer dynamics in regions of complex terrain, Thesis, Arizona State University, 2001.

Pardyjak, E. R. and Fernando, H. J. S.: The effect of surface type on the decay of turbulence in the surface layer during evening transition, in: Proc: 9th EMS Annual Meeting, 28 September-2 October 2009, Toulouse, France, 2009.

Pielke, R. A.: Mesoscale Meteorological Modeling. Academic Press, Amsterdam, 676 pp., 2nd Edition, 2002.

Pietersen, H. P., Vilà-Guerau de Arellano, J., Augustin, P., de Coster, O., Delbarre, O., Durand, P., Fourmentin, M., Gioli, B., Hartogensis, O., Lothon, M., Lohou, F., Pino, D., Ouwersloot, H. G, Reuder, J., and van de Boer, A.: Study of a prototypical convective boundary layer observed during BLLAST: contributions 
by large-scale forcing, submitted to Atmos. Chem. Phys. Discuss. 14, 19247-19291, doi:10.5194/acpd-14-19247-2014, 2014.

Pino, D., Jonker, H. J. J., Vilà-Guerau de Arellano, J., and Dosio, A.: Role of shear and the inversion strength during sunset turbulence over land: characteristic length scales, Bound.-Lay. Meteorol., 121, 537-556, 2006

Pope, S. B.: Turbulent Flows. Cambridge University Press, Cambridge, 771 pp., 2000.

Poulos, G. S., Blumen, W., Fritts, D. C., Lundquist, J. K., Sun, J., Burns, S., Nappo, C., Banta, R., Newsom, R., Cuxart, J., Terradellas, E., Balsley, B., and Jensen, M.: CASES-99: A Comprehensive Investigation of the Stable Nocturnal Boundary Layer, B. Am. Meteorol. Soc., 83, 555-581, 2002.

Reuder, J., Ablinger, M., Agustsson, H., Brisset, P., Brynjolfsson, S., Garhammer, M., Johannesson, T., Jonassen, M., Kuehnel, R., Laemmlein, S., de Lange, T., Lindenberg, C., Malardel, S., Mayer, S., Mueller, M., Olafsson, H., Roegnvaldsson, O., Schaeper, W., Spengler, T., Zaengl, G., and Egger, J.: FLOHOF 2007: An overview of the mesoscale meteorological field campaign at Hofsjökull, Central Iceland, Meteorol. Atmos. Phys., 116, 1-13, 2012a.

Reuder, J., Jonassen, M., and Olafsson, H.: The Small Unmanned Meteorological Observer SUMO: Recent Developments and Applications of a Micro-UAS for Atmospheric Boundary Layer Research, Acta Geophys., 60, 1454-1473, 2012b.

Rizza, U., Miglietta, M. M., Degrazia, G. A., Acevedo, O. C., and Marques, E. P.: Sunset decay of the convective turbulence with Large-Eddy Simulation under realistic conditions, Physica A, 392, 4481-4490, 2013.

Román-Cascón, C., Yagüe, C., Viana, S., Sastre, M., Maqueda, G. Lothon, M., and Gómara, I.: Near monochromatic ducted gravity waves associated with a convective system close to the Pyrénées, Q. J. R. Meteorol. Soc., doi:10.1002/qj.2441, accepted, 2014.

Saïd, F., Corsmeier, U., Kalthoff, N., Kottmeier, C., Lothon, M., Wieser, A., Hofherr, I., and Pascal, P.: ESCOMPTE experiment: intercomparison of four aircraft dynamical, thermodynamical, radiation and chemical measurements, Atmos. Res., 74, $217-$ 252, 2005

Sastre, M., Yagüe, C., Román-Cascón, C., Maqueda, G., Lothon, M., and Saïd, F.: Pressure perturbations and multi-scale analysis in the atmospheric boundary layer at the afternoon and evening transition during the BLLAST campaign, In: Proc: 20th Symposium on Boundary-Layers and Turbulence, 7-13 July, Boston, MA, USA, 2012.

Sastre, M., Steeneveld, G.-J., Yagüe, C., Román-Cascón, C., and Maqueda, G.: WRF tests on atmospheric boundary layer transitions during BLLAST campaign, Atmos. Chem. Phys. Discuss., in preparation, 2014

Seibert, P., Beyrich, F., Gryning, S.-E., Rasmussen, A., and Tercier, P.: Review and intercomparison of operational methods for the determination of the mixing height, Atmos. Environ., 34, 10011027, 2000.

Seity, Y., Brousseau, P., Malardel, S., Hello, G., Bénard, P., Bouttier, F., Lac, C., and Masson, V.: The AROME-France ConvectiveScale Operational Model, Mon. Weather Rev., 139, 976-991, 2011.

Shaw, W. J. and Barnard, J. C.: Scales of turbulence decay from observations and direct numerical simulations, Proc. of the 15th
Symposium on Boundary Layers and Turbulence, 15-19 July 2002, Wageningen, The Netherlands, 2002.

Soler, M. R., Infante, C., Buenestado, P., and Mahrt, L.: Observations of nocturnal drainage flow in a shallow gully, Bound.-Lay. Meteorol., 105, 253-273, 2002.

Sorbjan, Z.: Decay of convective turbulence revisited, Bound.-Lay. Meteorol., 82, 501-515, 1997.

Sorbjan, Z.: Gradient-based scales and similarity laws in the stable boundary layer, Q. J. R. Meteorol. Soc., 136, 1243-1254, 2010.

Sorbjan, Z.: The Height Correction of Similarity Functions in the Stable Boundary Layer, Bound.-Lay. Meteorol., 142, 21-31, 2012.

Steeneveld, G. J., Wokke, M. J. J., Groot Zwaaftink, C. D., Pijlman, S., Heusinkveld, B. G., Jacobs, A. F. G., and Holtslag, A. A. M.: Observations of the radiation divergence in the surface layer and its implication for its parameterization in numerical weather prediction models, J. Geophys. Res., 115, D06107, doi:10.1029/2009JD013074, 2010.

Stensrud, D. J.: Parameterization Schemes, Cambridge University Press, 459 pp., 2007.

Stull, R. B.: Energetics of entrainment across a density interface, J. Atmos. Sci., 33, 1260-1267, 1976.

Stull, R. B.: An Introduction to Boundary Layer Meteorology, Kluwer Academic Press, Dordrecht, 688 pp., 1988.

Sun, J., Burns, S. P., Delany, A. C., Oncley, S. P., Horst, T. W., and Lenschow, D. H.: Heat Balance in the Nocturnal Boundary Layer during CASES-99, J. Appl. Meteorol., 42, 1649-1666, 2003.

Sun, J., Mahrt, L., Banta, R. M., and Pichugina, Y. L.: Turbulence Regimes and Turbulence Intermittency in the Stable Boundary Layer during CASES-99, J. Atmos. Sci., 69, 338-351, 2012.

Svensson, G., Holtslag, a. a. M., Kumar, V., Mauritsen, T., Steeneveld, G. J., Angevine, W. M., Bazile, E., Beljaars, A., Bruijn, E. I. F., Cheng, A., Conangla, L., Cuxart, J., Ek, M., Falk, M. J., Freedman, F., Kitagawa, H., Larson, V. E., Lock, A., Mailhot, J., Masson, V., Park, S., Pleim, J., Söderberg, S., Weng, W., and Zampieri, M.: Evaluation of the Diurnal Cycle in the Atmospheric Boundary Layer Over Land as Represented by a Variety of Single-Column Models: The Second GABLS Experiment, Bound.-Lay. Meteorol., 140, 177-206, 2011.

Tennekes, H. and Lumley, J. L.: A First Course in Turbulence, The MIT Press, Cambridge, Massachussets, 1973.

Van de Boer, A., Moene, A. F., Schuttemeyer, D., and Graf, A.: Sensitivity and uncertainty of analytical footprint models according to a combined natural tracer and ensemble approach, Agr. Forest Meteorol., 169, 1-11, 2013.

Van den Kroonenberg, A. C., Martin, S., Beyrich, F., and Bange, J.: Spatially-Averaged Temperature Structure Parameter Over a Heterogeneous Surface Measured by an Unmanned Aerial Vehicle, Bound.-Lay. Meteorol., 142, 55-77, 2012.

Van de Wiel, B. J. H., Ronda, R. J., Moene, A. F., De Bruin, H. A. R., and Holtslag, A. A. M.: Intermittent turbulence and oscillations in the stable boundary layer over land. Part I: A bulk model, J. Atmos. Sci., 59, 942-958, 2002a.

Van de Wiel, B. J. H., Moene, A. F., Ronda, R. J., De Bruin, H. A. R., and Holtslag, A. A. M.: Intermittent turbulence and oscillations in the stable boundary layer over land. Part II: A system dynamics approach, J. Atmos. Sci., 59, 2567-2581, 2002b.

Van de Wiel, B. J. H., Moene, A. F., Hartogensis, O. K., De Bruin, H. A. R., and Holtslag, A. A. M.: Intermittent turbulence in the 
stable boundary layer over land. Part III: A classification for observations during CASES-99, J. Atmos. Sci., 60, 2509-2522, 2003.

van Driel, R. and Jonker, H. J. J.: Convective Boundary Layers Driven by Nonstationary Surface Heat Fluxes, J. Atmos. Sci., 68, 727-738, 2011.

Van Heerwaarden, C. C., Moene, A. F., and Holtslag, A. A. M.: Interactions between dry-air entrainment, surface evaporation and convective boundary-layer development, Q. J. R. Meteorol. Soc., 135, 1277-1291, 2009.

Van Ulden, A. P. and Wieringa, J.: Atmospheric boundary layer research at Cabauw, Bound.-Lay. Meteorol., 78, 39-69, 1996.

Viana, S., Yagüe, C., and Maqueda, G.: Propagation and effects of a mesoscale gravity-wave over a weakly-stratified nocturnal boundary layer during SABLES2006 field campaign, Bound.Lay. Meteorol., 133, 165-188, 2009.

Viana, S., Terradellas, E., and Yagüe, C.: Analysis of Gravity Waves Generated at the Top of a Drainage Flow, J. Atmos. Sci., 67, 3949-3966, 2010.

Vilà-Guerau de Arellano, J., Dosio, A., Vinuesa, J.-F., Holtslag, A. A. M., and Galmarini, S.: The dispersion of chemically reactive species in the atmospheric boundary layer, Meteorol. Atmos. Phys., 87, 23-38, 2004.
Vilà-Guerau de Arellano, J., van den Dries, K., and Pino, D.: On inferring isoprene emission surface flux from atmospheric boundary layer concentration measurements, Atmos. Chem. Phys., 9, 3629-3640, doi:10.5194/acp-9-3629-2009, 2009.

Whiteman, C. D.,: Observations of Thermally Developed Wind Systems in Mountainous Terrain. Chapter 2 in Atmospheric Processes Over Complex Terrain, edited by: Blumen, W., Meteorological Monographs, 23, no. 45. American Meteorological Society, Boston, Massachusetts, 5-42, 1990.

Willis, G. E. and Deardorff, J. W.: A laboratory model of diffusion into the convective planetary boundary layer, Q. J. R. Meteorol. Soc., 102, 427-445, 1976.

Wyngaard, J. C.: Turbulence in the atmosphere. Cambridge University Press, England, 393 pp., 2010.

Yagüe, C. and Cano, J.: Eddy transfer processes in the atmospheric boundary layer, Atmos. Environ., 28, 1275-1289, 1994.

Zhu, P. and Albrecht, B.: A theoretical and observational analysis on the formation of fair-weather cumuli, J. Atmos. Sci., 59, 19832005, 2002. 